Article

\title{
Repeated Intrastriatal Botulinum Neurotoxin-A Injection in Hemiparkinsonian Rats Increased the Beneficial Effect on Rotational Behavior
}

\author{
Alexander Hawlitschka ${ }^{1}$, Carsten Holzmann ${ }^{2} \mathbb{D}$, Andreas Wree ${ }^{1, *}$ and Veronica Antipova ${ }^{1,3}$ (D) \\ 1 Institute of Anatomy, Rostock University Medical Center, D-18057 Rostock, Germany; \\ alexander.hawlitschka@med.uni-rostock.de (A.H.); veronica.antipova@medunigraz.at (V.A.) \\ 2 Institute of Medical Genetics, Rostock University Medical Center, D-18057 Rostock, Germany; \\ carsten.holzmann@med.uni-rostock.de \\ 3 Gottfried Schatz Research Center for Cell Signaling, Metabolism and Aging, Macroscopic and Clinical \\ Anatomy, Medical University of Graz, A-8010 Graz, Austria \\ * Correspondence: andreas.wree@med.uni-rostock.de; Tel.: +49-3814948400
}

Received: 22 August 2018; Accepted: 8 September 2018; Published: 11 September 2018

\begin{abstract}
Injection of botulinum neurotoxin-A (BoNT-A) into the striatum of hemiparkinsonian (hemi-PD) rats reduced apomorphine-induced rotation behavior significantly, for at least 3 months. Thereafter, rotation behavior increased again. We injected hemi-PD rats with $1 \mathrm{ng}$ BoNT-A twice, the second injection following 6 months after the first one and tested the rats for apomorphine-induced rotations and spontaneous motor behaviors, i.e., corridor task and stepping test. To test the hypothesis that BoNT-A reduced striatal hypercholinism in hemi-PD rats, the acetylcholinesterase inhibitor donepezil was injected prior to separate apomorphine-induced rotation tests. In hemi-PD rats, the first BoNT-A injection led to a clear reduction of the apomorphine-induced rotations, and the second BoNT-A injection to a more massive and prolonged reaction. In hemi-PD rats whose apomorphine-induced rotation behavior was strongly reduced by an intrastriatal BoNT-A, subsequent donepezil injections led to significant increases of the rotation rate. Concerning corridor task and stepping test, neither first nor second BoNT-A injections changed hemi-PD rats' behavior significantly. The data give evidence for the possibility of repeated intrastriatal administrations of BoNT-A, for treatment of motor symptoms in experimental hemi-PD over a longer time.
\end{abstract}

Keywords: botulinum neurotoxin-A; striatum; basal ganglia; donepezil; acetylcholine; 6-OHDA

Key Contribution: In hemiparkinsonian rats the temporal positive effect of repeated intrastriatal BoNT-A application on apomorphine-induced rotations and spontaneous motor behaviors was studied for the first time.

\section{Introduction}

Parkinson's disease (PD) is the most frequent neurodegenerative movement disorder, which mainly affects movement ability. PD is associated with a loss of dopaminergic neurons in the substantia nigra pars compacta (SNpc), leading to a lack of dopaminergic inhibition of tonically active cholinergic interneurons in the striatum $(\mathrm{CPu})$ (Figure 1A,B). This causes a hypercholinism in the $\mathrm{CPu}$, which is thought to contribute to the majority of motor symptoms in PD [1-5] (Figure 1B). Classic anticholinergic treatments ameliorate motor symptoms of PD, but acting systemically they also entail numerous unwanted side effects [6-9].

Botulinum neurotoxin-A (BoNT-A) cleaves synaptosomal-associated protein-25 (SNAP-25), a component of the vesicle fusion apparatus of the cholinergic presynaptic membrane. Therefore, 
it inhibits the release of acetylcholine $(\mathrm{ACh})$ in the peripheral nervous system $[10,11]$, and as we hypothesized in the central nervous system as well [12] (Figure 1C). Intrastriatal injection of $1 \mathrm{ng}$ BoNT-A in hemiparkinsonian (hemi-PD) rats reverses apomorphine-induced rotations for at least 3 months [12-17]. During a time frame of 12 months after BoNT-A treatment, hemi-PD rats showed a gradual recurrence of the apomorphine-induced rotation rate [12-14].
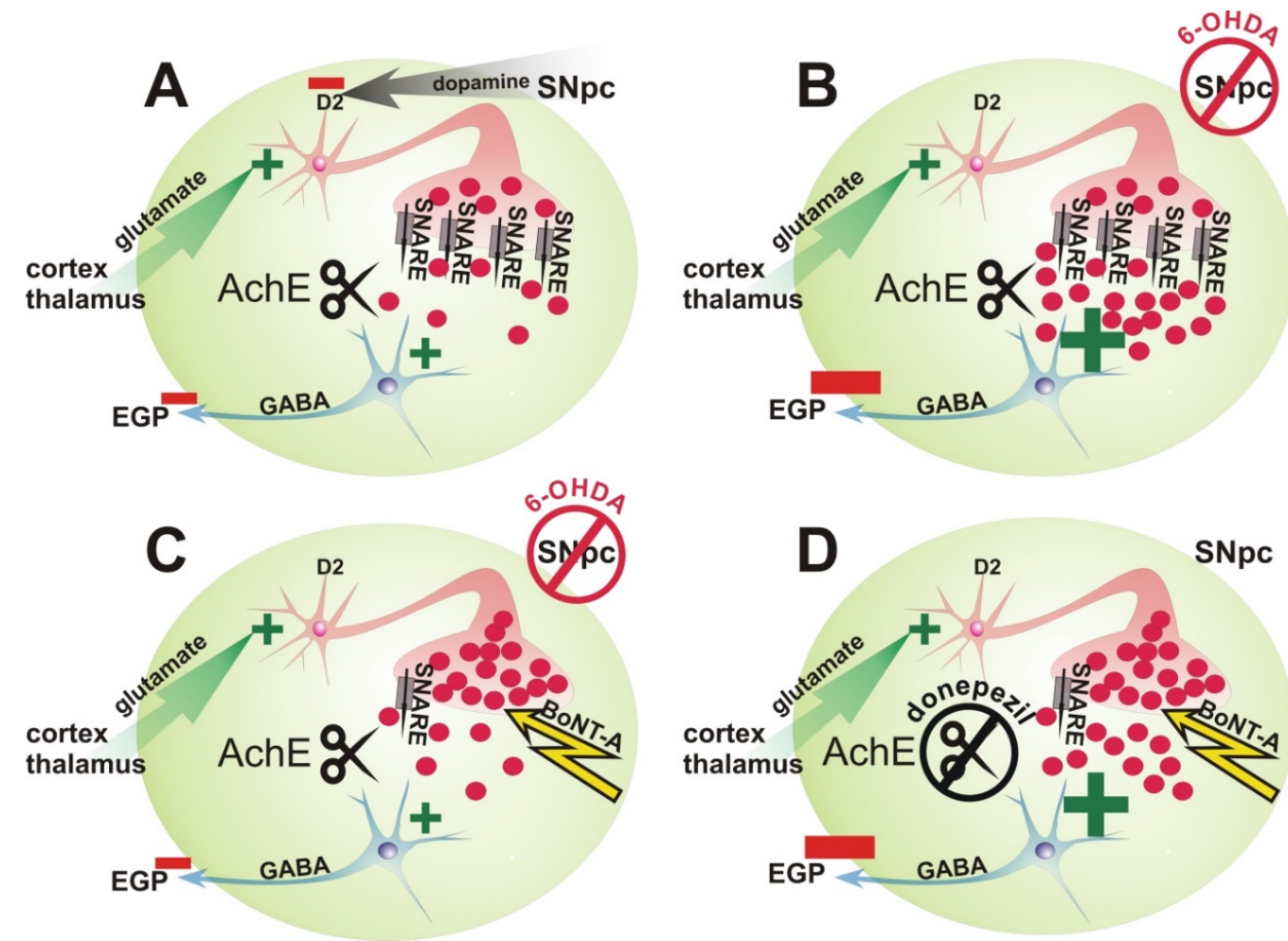

Figure 1. Theoretical concept of the ACh-dependency of the reduction of the apomorphine-induced rotation rate after unilateral BoNT-A treatment of hemiparkinsonian (hemi-PD) rats. (A-D) Scheme of the indirect pathway of the basal ganglia circuitry. Neurons, efferences and afferences of the striatum (green oval area) relevant for our experiments are shown. A large cholinergic interneuron is depicted with a stylized presynapse (red), the red circles representing ACh. The rectangles with an arrow (SNARE) symbolize the entirety of the $N$-ethylmaleimide-sensitive-factor attachment receptor complex, which conveys the fusion of transmitter vesicles with the presynaptic membrane. The scissors named with "AChE" represent acetylcholinesterase which cleaves $\mathrm{ACh}$, and the blue neuron a medium sized spiny projection neuron (MSN), which inhibits the globus pallidus externus (EGP) neurons by GABA. (A) Under normal conditions tonically active cholinergic interneurons excite MSNs by release of ACh. These cholinergic interneurons are excited by glutamatergic input of motor, sensory, and prefrontal cortices and thalamus. Owing to their $\mathrm{D}_{2}$ receptors, cholinergic interneurons are inhibited by dopaminergic input from the substantia nigra pars compacta (SNpc). (B) After lesion of the SNpc with 6-OHDA the dopaminergic input to the striatum, and consequently, the inhibition of cholinergic interneurons is reduced, leading to a striatal extracellular hypercholinism, symbolized by a higher number of red circles. Therefore, GABA-ergic projection neurons to the EGP become overactive. (C) The injection of BoNT-A directly into the striatum cleaves the SNAP-25, an essential component of the SNARE complex in cholinergic presynaptic boutons. In consequence, the extracellular amount of ACh and the inhibition of the EGP should normalize. (D) After administration of the blood-brain barrier passing acethylcholinesterase inhibitor donepezil, the BoNT-A-induced reduction of extracellular ACh in hemi-PD rat striatum should be at least partially reversed, and the extracellular ACh concentration in the striatum increased again. 
In this study, two aspects of hemi-PD and BoNT treatment were evaluated. First, we tested whether repeated intrastriatal BoNT-A injections were able to improve motor behavior in hemi-PD rats for a longer time period, resembling used clinical practice for BoNT-A treatments [18,19]. Thus, hemi-PD rats were intrastriatally injected with $1 \mathrm{ng}$ BoNT-A 1 month and 7 months following 6-hydroxydopamine (6-OHDA) lesion (Figure 2), and underwent the apomorphine-induced rotation test, as well as the stepping test and corridor task for spontaneous motor behaviors.

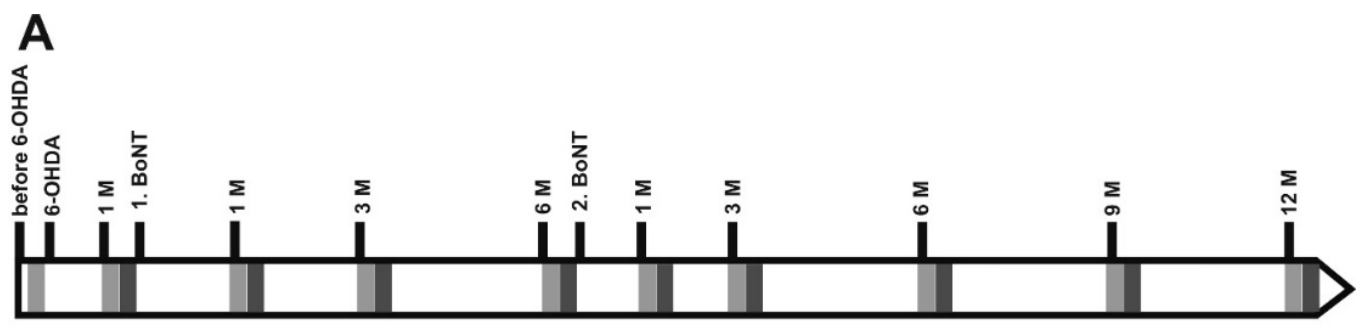

B

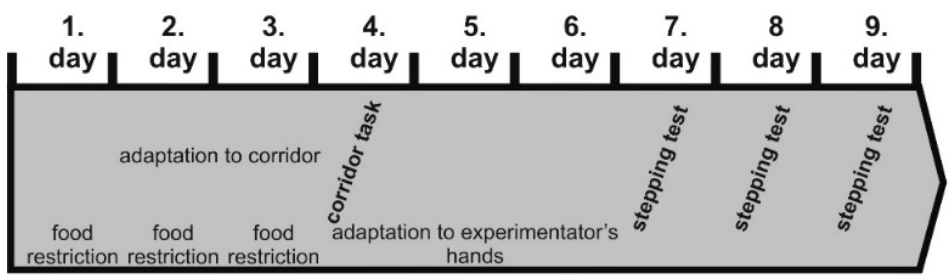

C

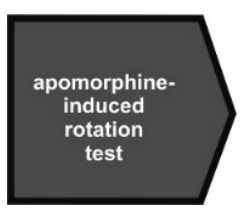

Figure 2. (A) Time points of 6-OHDA lesion and behavioral tests in rats after first (1. BoNT) and second (2. BoNT) BoNT-A or sham injection. Light grey rectangles symbolize batteries of corridor task and stepping test, dark grey rectangles apomorphine-induced rotation test. (B) The spontaneous behavior tests were performed as follows: Each series lasted 9 days. During the first 3 days, rats were food restricted and then 2 days adapted to the corridor task apparatus for 10 min each. Next day, the final corridor task was performed for $5 \mathrm{~min}$. At the following 3 days, rats were handled by the experimenter for $5 \mathrm{~min}$ each day, and on the following 3 days, rats underwent the stepping test twice a day. (C) Finally, apomorphine-induced rotation test was performed for $40 \mathrm{~min}$.

In the second set of experiments, the effect of donepezil on apomorphine-induced rotation behavior in hemi-PD rats was investigated. Doing so, we wanted to test whether the decrease of the apomorphine-induced rotation rate after intrastriatal BoNT-A injection in hemi-PD rats was due to a reduction of extracellular $\mathrm{ACh}$ content in the $\mathrm{CPu}$. We supposed that the observed decrease in the apomorphine-induced turning rate in BoNT-A-injected hemi-PD rats, was attributed to a reduction of $\mathrm{ACh}$ content in the treated $\mathrm{CPu}$. However, direct evidence for a decrease of the extracellular ACh concentration in the $\mathrm{CPu}$ in hemi-PD rats after BoNT-A application, and a correlation between the hypothesized ACh decrease and the reduction of the apomorphine-induced turning rate, was not provided yet.

Assuming the observed beneficial effect of BoNT-A was a result of a reduction of striatal extracellular ACh content, an increase of the extracellular ACh should abrogate this effect. Experimentally, such an increase of ACh in the synaptic clefts of the $\mathrm{CPu}$ was provoked by application of the blood-brain barrier passing acetylcholinesterase (AChE) inhibitor donepezil (Figure 1D) [20]. Hemi-PD BoNT-A-treated rats underwent the apomorphine-induced rotation test up to 9 months after 
BoNT-A, and each again $72 \mathrm{~h}$ later following injection of donepezil 1 or $24 \mathrm{~h}$ ahead. Rotations of both tests were compared to separate the donepezil effect.

There is consistent information about the pharmacological half-life of donepezil in man, but not in rats. In the product information of donepezil-based medications (Aricept ${ }^{\circledR}$, Full Prescribing Information; $2016 \mathrm{http} / /$ /www.aricept.com/prescribing-and-patient-info), as well as in several publications [20-25], the half-life $\left(\mathrm{t}_{1 / 2}\right)$ is denoted at about $70 \mathrm{~h}$ in man. However, in rats, divergent half-lifes were reported either in the range of 2 up to $3.5 \mathrm{~h}$ [26-28] or about $24 \mathrm{~h} \mathrm{[29].} \mathrm{To} \mathrm{circumvent}$ the divergent information about the $t_{1 / 2}$ of donepezil, we studied experimental groups which were administered donepezil or sham donepezil $24 \mathrm{~h}$ or $1 \mathrm{~h}$ prior to the second rotation test at each monitoring point (Figures 7 and 9).

\section{Results}

\subsection{Repetitive Intrastriatal BoNT-A Injection in Hemi-PD Rats}

\subsubsection{Body Weight}

Both intrastriatal applications of BoNT-A were tolerated well by the animals and did not result in health problems. Thus, the development of body weight in hemi-PD rats was neither significantly altered by the first nor second BoNT-A injections, compared with sham-injected controls $\left(\mathrm{F}_{1,20}=1.091\right.$, $p=0.31$ ). (Figure 3).

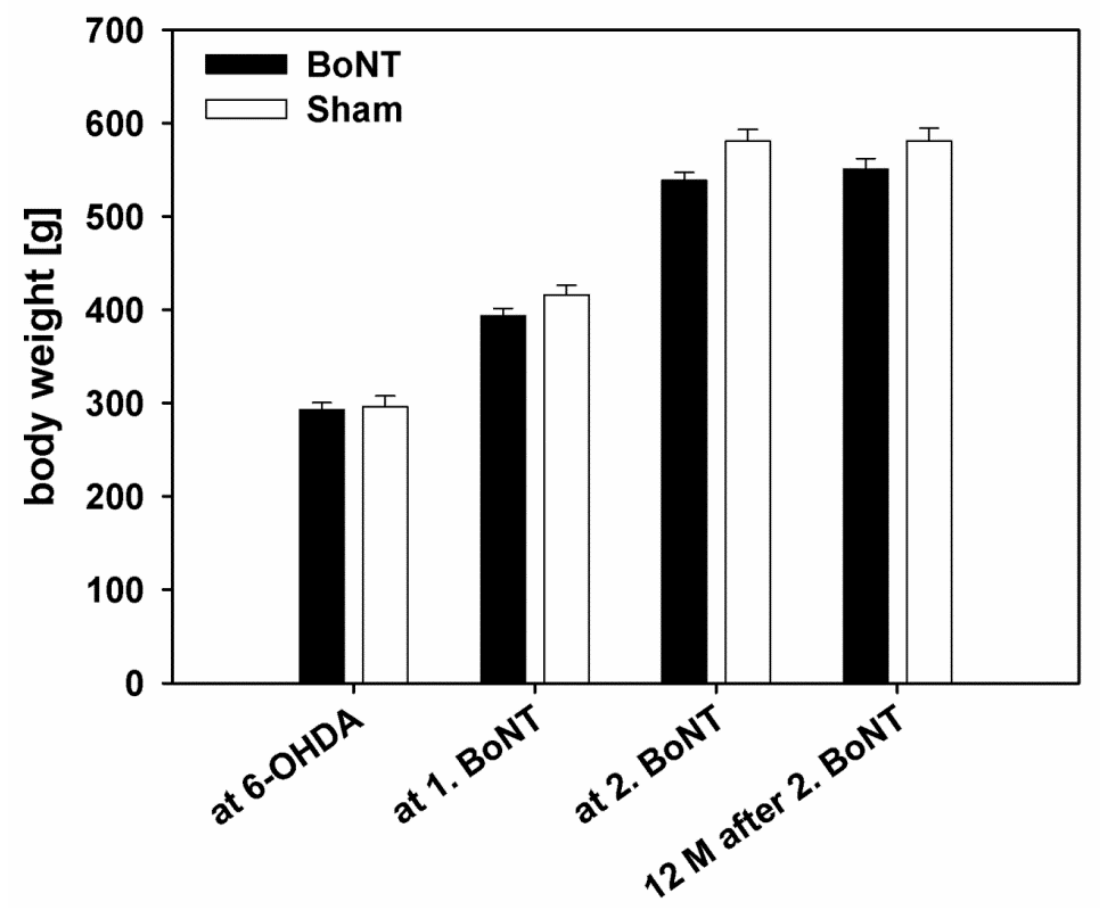

Figure 3. Body weights of both groups evaluated at the following time points: day of 6-OHDA injection, day of first (1. BoNT) and second (2. BoNT) BoNT-A or vehicle injections, as well as 12 months after the second BoNT-A or vehicle applications. Repetitive BoNT-A injection did not alter body weights, compared with vehicle injection in hemi-PD rats. All data are represented as mean $\pm \mathrm{SEM}$.

\subsubsection{Apomorphine-Induced Rotation Test}

Hemi-PD rats intrastriatally treated with BoNT-A had less apomorphine-induced rotation, compared with sham-injected animals $\left(\mathrm{F}_{1,20}=4.385, p=0.048\right)$. Hemi-PD rats 4 weeks after 6-OHDA, showed about 6 apomorphine-induced turns per minute. In the present study, hemi-PD rats 1 month after BoNT-A showed about 2 apomorphine-induced rotations per minute, and thereby significant 
lower values compared with sham-injected hemi-PD rats $(p=0.001)$. Thereafter, a progressive resurgence of the BoNT-A-induced reduction of the apomorphine-induced rotation rate occurred, reaching values identical to sham-injected rats at 6 months (Figure 4). However, 6 months after the second BoNT-A injection using the same coordinates as before, an even more pronounced and significant decline of the turning rate to about 2 was found, resembling the 1-month value of the first BoNT-A injection (Figure 4). To fit the rotation data by a regression line, the parameter rpm/day was calculated for every post BoNT-A test point after the first and second application, and both slopes (m) of the regressions were calculated. The time dependent slope of the apomorphine-induced rotation rates after the first BoNT-A injection was $\mathrm{m}=0.0296 \mathrm{rpm} \mathrm{d}^{-1}$, which after the second BoNT-A injection was significantly flatter $\left(\mathrm{m}=0.0136 \mathrm{rpm} \mathrm{d}^{-1}\right)\left(\mathrm{t}_{20}=2.531, p=0.02\right)$ (dashed lines in Figure 4$)$.

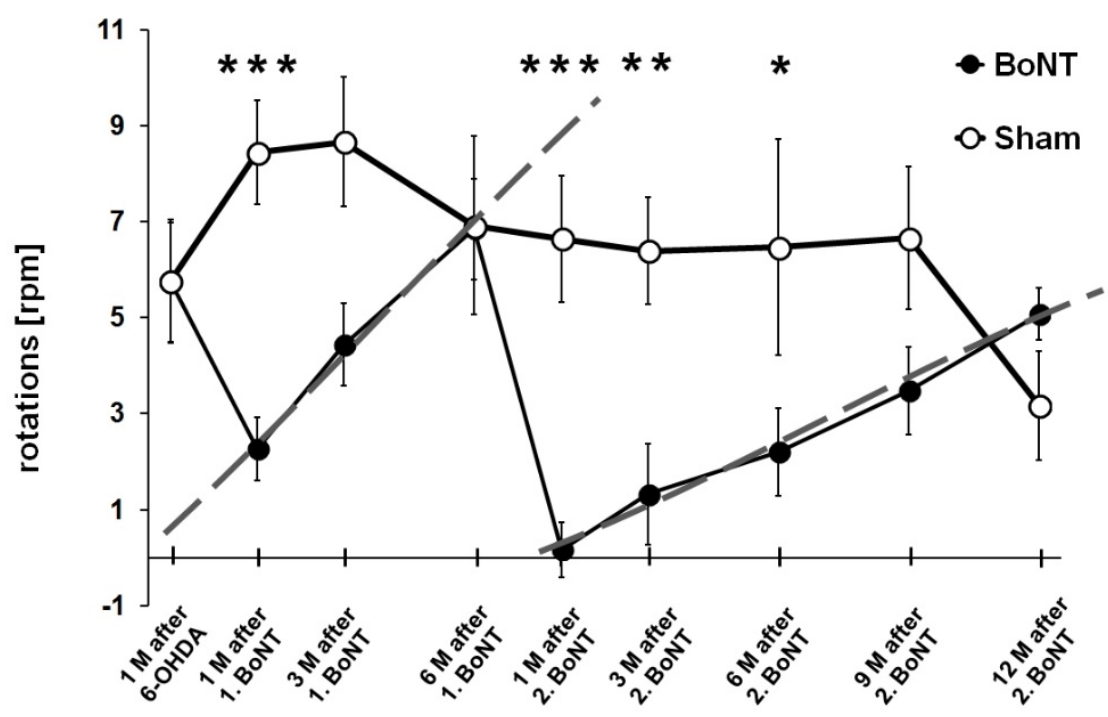

Figure 4. Apomorphine-induced rotation rates of hemi-PD rats repetitively treated with intrastriatal BoNT-A ( $n=11$, black dots) or vehicle ( $n=6$, light dots) 1 month and 7 months after 6-OHDA lesion. Vehicle solution has no significant effect on apomorphine-induced rotation behavior in hemi-PD rats. First BoNT-A reduces the turning rate significantly and temporally, the effect diminishing after 6 months. The effect of the 2. BoNT-A injection is more distinct and lasts longer than the 1. BoNT. Dashed grey lines mark linear regressions of the respective time dependencies of the apomorphine-induced rotation rates after 1 . and 2. BoNT-A. Asterisks indicate significant difference $\left({ }^{*} p<0.05,{ }^{* *} p<0.01,{ }^{* * *} p<0.001\right)$. Data are represented as mean \pm SEM.

\subsubsection{Spontaneous Motor Tests}

\section{Adjusting Steps}

The stepping test was used to evaluate forelimb akinesia, which is most likely due to bradykinesia of the affected limb [30-33]. Adjusting steps were measured on the non-lesioned and lesioned sides, for each animal group (BoNT-A- and sham-treated hemi-PD rats), in the forehand and backhand directions.

Before 6-OHDA lesion, no difference in the number of adjusting steps for the left and right forepaws, in forward and backward directions, was observed in either group (Figure 5A-D). All rats made about 9-12 steps in forward and in backward directions, with their left and right forepaws.

Right side 6-OHDA lesion induced impairment in the performance of the left forelimb (contralateral to 6-OHDA, Figure 5A,C) during the adjusting step when the rats were moved forward and backward by the experimenter, the right forelimb (ipsilateral to 6-OHDA lesion) being unaffected (Figure 5B,D). No significant improvement or worsening of the left forepaw movements was monitored after the first, as well as after the second intrastriatal BoNT-A or sham injection (Figure 5A,C). At the same time, in 6-OHDA-lesioned rats, side stepping movements of the right forepaw in both forehand 
and backhand directions, were generally neither affected by ipsilateral BoNT-A nor sham injection up to 12 months (Figure 5B,D), with exception of single time points.
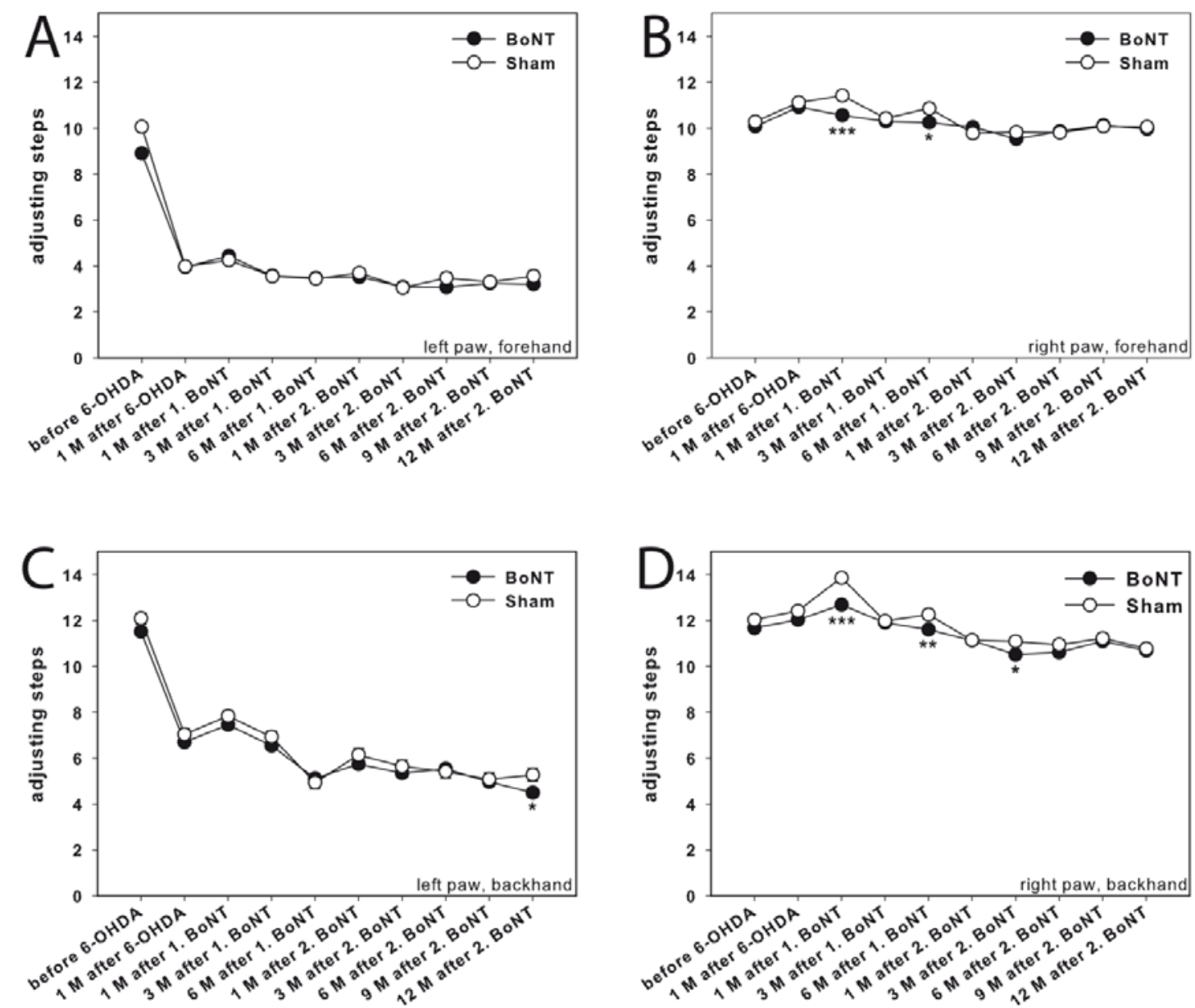

Figure 5. Stepping test in hemi-PD rats treated with repetitive intrastriatal BoNT-A or vehicle. In unlesioned rats, about 10-12 adjusting steps for the left (A,C) and right (B,D) forelimbs in forehand and backhand directions were counted. In hemi-PD rats, the use of the left forepaw was impaired in both the forehand (A) and backhand (C) directions. Neither 1. nor 2. BoNT-A nor sham injection changed the impairment of left and right forelimb steps in both the forehand $(\mathbf{A}, \mathbf{C})$ and backhand $(\mathbf{B}, \mathbf{D})$ directions in hemi-PD rats. Asterisks indicate significant differences compared to the sham group $\left.{ }^{*} p<0.05,{ }^{* *} p<0.01,{ }^{* * *} p<0.001\right)$. Data are represented as mean $\pm \mathrm{SEM}$.

\section{Corridor Task}

Two weeks before the 6-OHDA injection, rats were tested in the adjacent version of the corridor task. Preoperative screening showed that all animals performed an equivalent number of retrievals from each side of the corridor (about $50 \%$ of the total retrievals from either side) (Figure 6). Animals with right side hemi-PD exhibited a strong neglect of the left corridor side (contralateral to lesion): Only about $5 \%$ of retrievals were measured on the left side (Figure 6).

Neither the first ipsilateral intrastriatal BoNT-A nor sham injections in hemi-PD rats, improved a contralateral sensorimotor integration up to 6 months significantly (Figure 6). Moreover, the second intrastriatal injection of BoNT-A or vehicle demonstrated non-significant effects on sensorimotor (spatial) neglect for the side contralateral to the lesion during the next 12 months post-injection (Figure 6). 


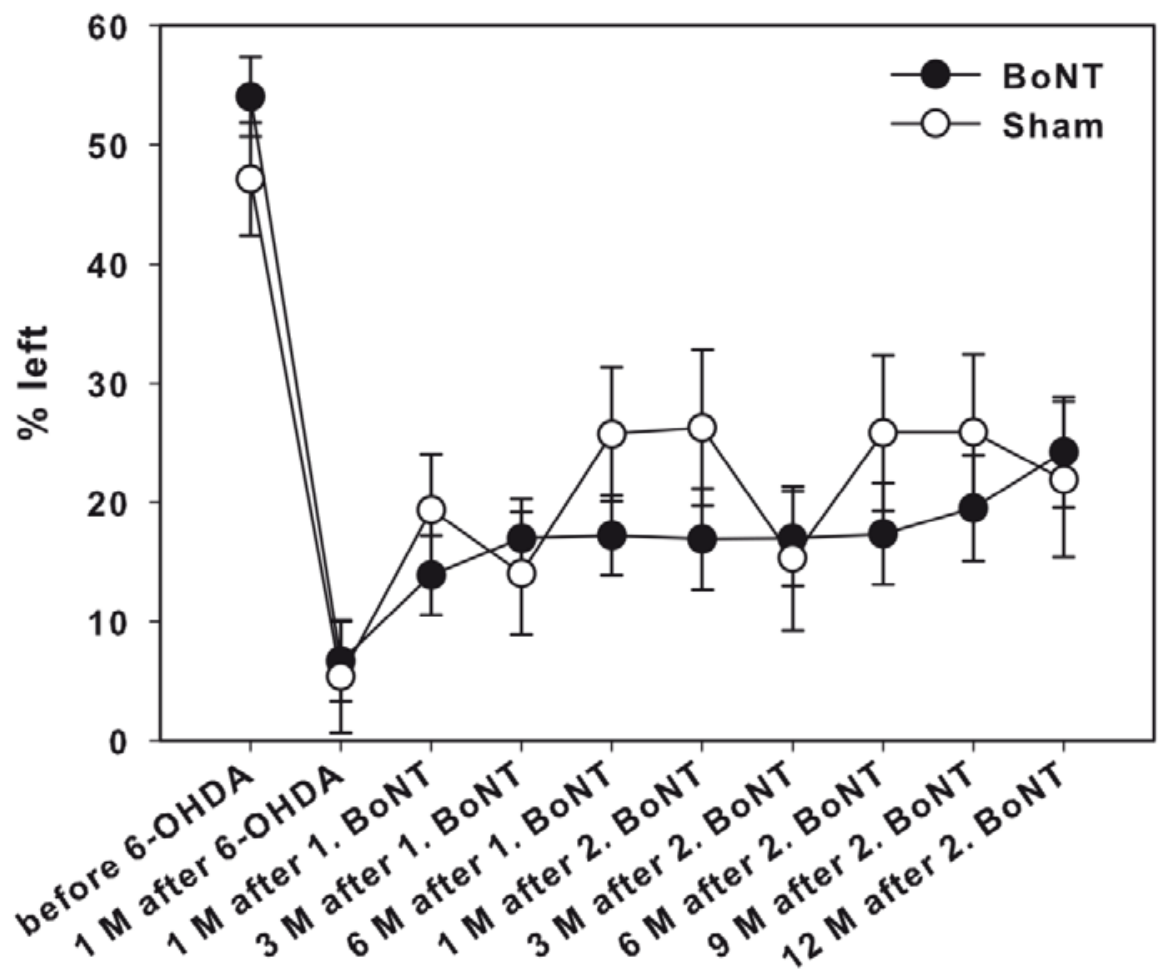

Figure 6. Corridor task in hemi-PD rats repetitively treated with intrastriatal BoNT-A or vehicle. Before 6-OHDA lesion, all animals equally retrieved pellets from either the left or right sides of the corridor apparatus. Right side hemi-PD rats significantly neglected the left corridor side. Neither 1. nor 2. BoNT-A nor sham injection improved contralateral sensorimotor integration in hemi-PD rats. Data are represented as mean \pm SEM.

\subsection{Influence of Donepezil on Apomorphine-Induced Rotation Behavior}

In the second experiment, we investigated whether it could be the reduced extracellular ACh concentration that caused the reduction of the BoNT-A-related apomorphine-induced rotation rate in hemi-PD rats. We compared the results of two apomorphine-induced rotation tests performed with an interval of $72 \mathrm{~h}$, whereby the first was performed without additional donepezil, and the second following injection of donepezil ( $2 \mathrm{mg} \mathrm{kg}^{-1}$ body weight (BW)), either $24 \mathrm{~h}$ or $1 \mathrm{~h}$ before apomorphine.

\subsubsection{Reaction of Rats to Donepezil}

Animals' reaction to $2 \mathrm{mg} \mathrm{kg}^{-1} \mathrm{BW}$ donepezil was qualitatively evaluated. Starting about 8-10 min after i.p. injection, rats showed donepezil-related gnawing. This donepezil-induced gnawing behavior lasted approximately for about $2.5 \mathrm{~h}$. We also measured a decline of the body temperature of approximately $1^{\circ} \mathrm{C}, 1 \mathrm{~h}$ after donepezil administration. Tremor, salivation, lacrimation, and increased defecation, indicative for threefold higher donepezil dosages used by others were not seen $[23,27,34-36]$. General motor activity seemed uninfluenced by donepezil. Moreover, no fasciculations mentioned after daily oral application of $2.5 \mathrm{mg} \mathrm{kg}^{-1}$ [37] were seen after a single dose applied i.p., as used in our study. 


\subsubsection{Donepezil Injection $24 \mathrm{~h}$ Prior to the Second Rotation Test}

Two groups of hemi-PD rats were used. One group was intrastriatally injected with $1 \mathrm{ng}$ BoNT-A (group 6-OHDA + BoNT-A), and the other with the solvent of BoNT-A (group 6-OHDA + sham BoNT-A). At 1, 2, 3, and 4 months after BoNT-A or vehicle application, the apomorphine-induced rotation rate was measured, and at each time point $48 \mathrm{~h}$ later, $2 \mathrm{mg} \mathrm{kg}^{-1} \mathrm{BW}$ donepezil was injected i.p., and a further $24 \mathrm{~h}$ later, the second apomorphine-induced rotation test was performed (Figure 7).

\section{A}

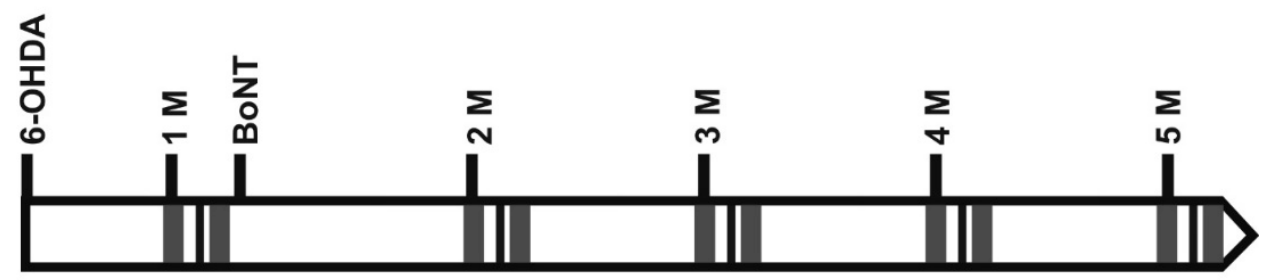

B

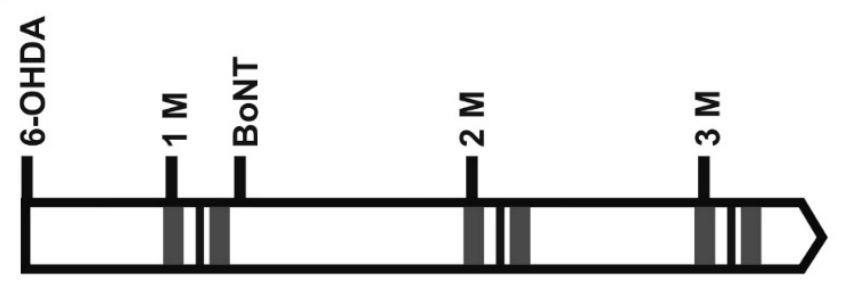

C

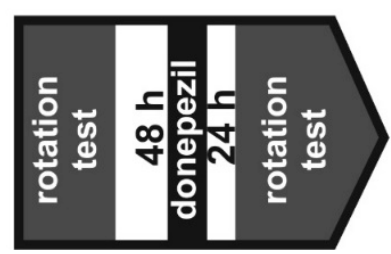

Figure 7. Time points of repetitive apomorphine-induced rotations (dark grey rectangles) in hemi-PD rats, before and after BoNT-A or sham injection, under the influence of donepezil (A) or sham donepezil (B). (C) The two apomorphine-induced rotations were performed as follows: Apomorphine rotations were tested $72 \mathrm{~h}$ apart. Furthermore, $24 \mathrm{~h}$ before the second rotation test, donepezil or vehicle was injected.

As expected, intrastriatal BoNT-A reduced apomorphine-induced rotations in hemi-PD rats (Figure 8A). Seventy-two $\mathrm{h}$ later the same rats having received donepezil $24 \mathrm{~h}$ before, showed significantly increased rotation rates (Figure $8 \mathrm{~A}$ ).

However, a comparable donepezil effect in apomorphine-induced rotations was also found in sham BoNT-A-treated hemi-PD rats (Figure 8A). Significant differences between the two consecutive rotation tests-first without and second with donepezil—were found for the monitoring points at 1 and 2 months after the BoNT-A or sham BoNT-A administration (Figure 8A). 

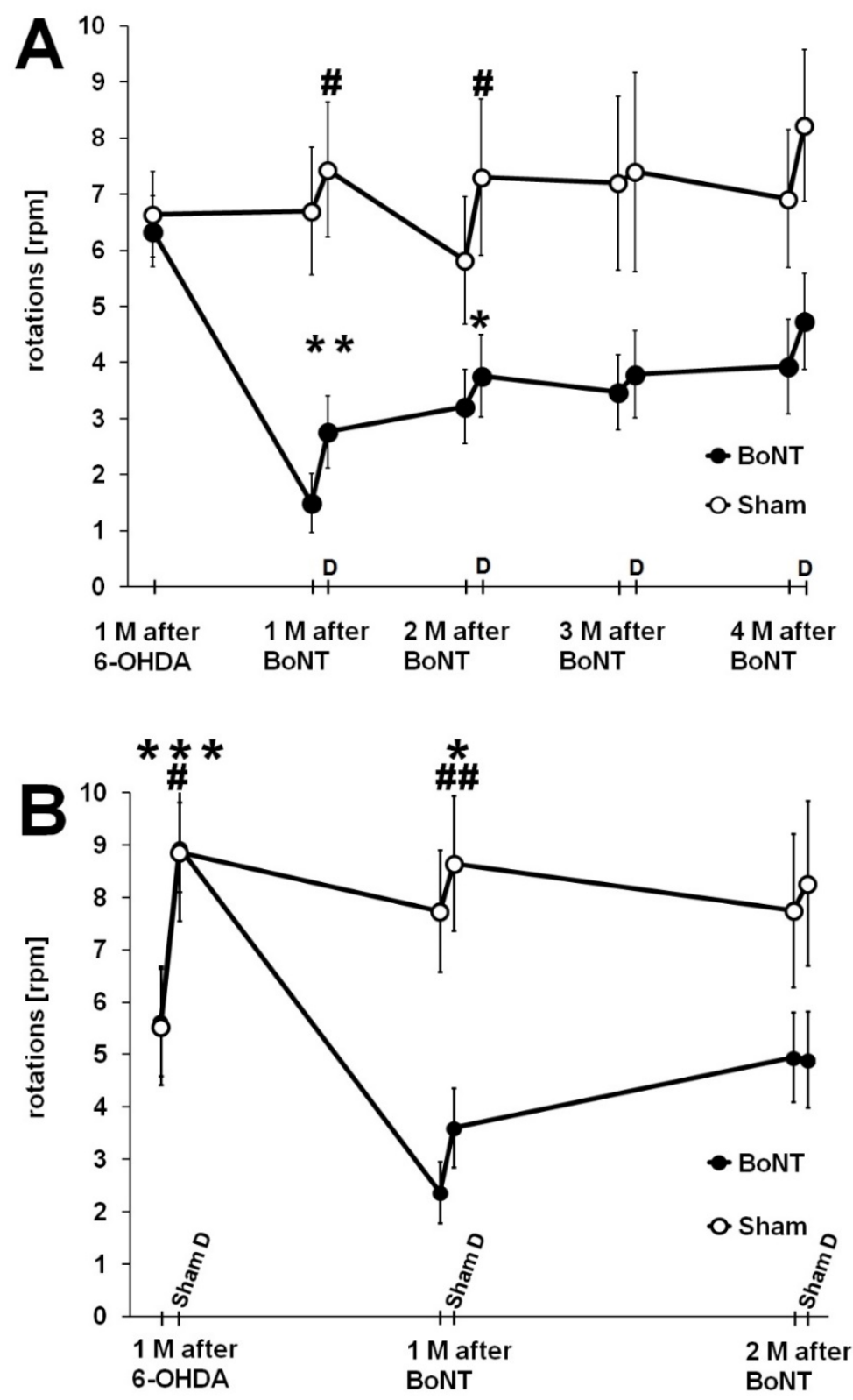

Figure 8. (A) Hemi-PD rats treated with intrastriatal BoNT-A (black dots) or vehicle (light dots) underwent apomorphine-induced rotation tests, before and 1 to 4 months after BoNT-A or sham BoNT-A. In the second apomorphine-induced rotation test under the influence of donepezil ( $2 \mathrm{mg} \mathrm{kg}^{-1} \mathrm{BW}$ ) injected $24 \mathrm{~h}$ ahead, the rotation rate significantly increased at time points 1 and 2 months after BoNT-A, as well as after sham BoNT-A. Asterisks mark significant donepezil-induced changes of the turning rate between the two associated rotations in the group which was treated with BoNT-A, hashes mark those in the group treated with sham BoNT-A. (B) Hemi-PD rats treated with intrastriatal BoNT-A (black dots) or vehicle (light dots) underwent apomorphine-induced rotation test, before and 1 to 2 months after BoNT-A or sham BoNT-A. In the second apomorphine-induced rotation test under the influence of sham donepezil injected $24 \mathrm{~h}$ ahead, rotation rates significantly increased at time points 1 month after 6-OHDA and 1 month after BoNT-A. Asterisks mark significant sham donepezil-induced changes of the turning rate between the two rotation tests of the BoNT-A-treated group, hashes mark significant changes in the group treated with sham BoNT-A. Asterisks and hashes indicate significant differences $\left({ }^{*} p<0.05,{ }^{* *} p<0.01,{ }^{* * *} p<0.001{ }^{*}{ }^{*} p<0.05,{ }^{\# \#} p<0.01\right)$. Data are represented as mean \pm SEM. 


\subsubsection{Sham Donepezil Injection $24 \mathrm{~h}$ Prior to the Second Rotation Test}

Using a comparable experimental design, except for the donepezil injection prior to the second rotation, rats were injected with $0.9 \% \mathrm{NaCl}$ solution $24 \mathrm{~h}$ prior to the second rotation test at the monitoring points 1 month after the 6-OHDA, and 1 and 3 months after BoNT-A injection in hemi-PD rats (Figure 8B). Remarkably, in these experiments we measured significant increases in the apomorphine-induced rotations $24 \mathrm{~h}$ after sham donepezil injection, 1 month after 6-OHDA lesion, as well as 1 month after BoNT-A injection or sham BoNT-A injection (Figure 8B).

\subsubsection{Donepezil Injection $1 \mathrm{~h}$ Prior to the Second Rotation Test}

Three experimental groups of hemi-PD rats were studied (Figure 9): The first group $(n=6)$ was BoNT-A-treated 1 month after the 6-OHDA and received donepezil $1 \mathrm{~h}$ prior to the second rotation tests at every monitoring point (Figure 10A). The second group $(n=6)$ was sham BoNT-A-treated 1 month after 6-OHDA and received donepezil $1 \mathrm{~h}$ prior to the second rotation tests (Figure 10B). The third group $(n=6)$ was BoNT-A-treated 1 month after induction of hemi-PD and received sham donepezil $(0.9 \% \mathrm{NaCl}) 1 \mathrm{~h}$ prior to the second rotation tests at every monitoring point (Figure 10C). One $\mathrm{h}$ after injection of $2 \mathrm{mg} \mathrm{kg}^{-1}$ BW donepezil, sham BoNT-A-treated hemi-PD rats showed a significant and considerable decrease of the apomorphine-induced rotation rate of about 3 to $4 \mathrm{rpm}$ (rotations in anti-clockwise direction), compared to values measured $72 \mathrm{~h}$ before (Figure 10B). One $\mathrm{h}$ after donepezil injection BoNT-A-treated hemi-PD rats only tentatively showed a decline of the turning rate, these changes being mostly insignificant (Figure 10A). Only 9 months after BoNT-A treatment, additional donepezil affected rotation behavior significantly, when the BoNT-A effect had nearly vanished (Figure 10A). Regarding BoNT-A-treated hemi-PD rats, which were injected with sham donepezil $1 \mathrm{~h}$ prior, a second rotation test at neither monitoring point showed significant changes in the turning rates (Figure 10C).

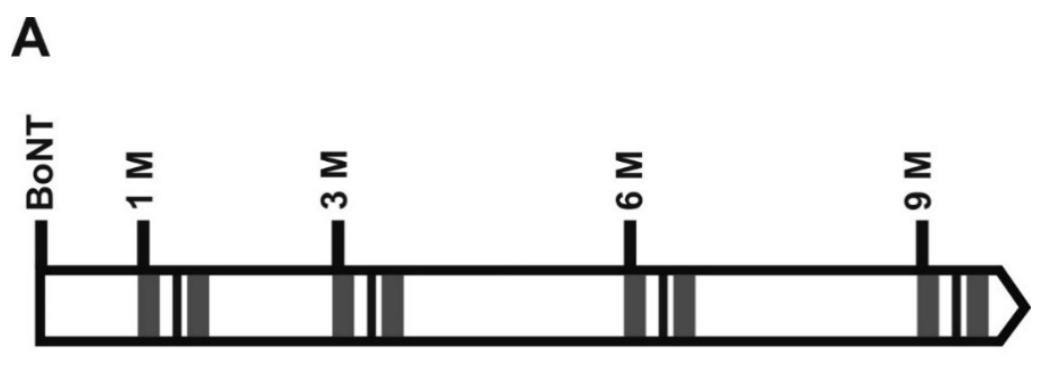

B

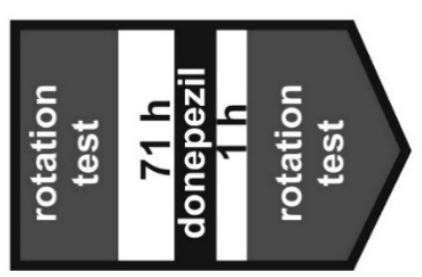

Figure 9. (A) Time points of repetitive apomorphine-induced rotations (dark grey rectangles) in hemi-PD rats, before and after BoNT-A or sham injection, under the influence of donepezil or sham donepezil. (B) The two apomorphine-induced rotations were performed as follows: Apomorphine rotations were tested $72 \mathrm{~h}$ apart. One $\mathrm{h}$ before the second rotation test, donepezil or vehicle was injected. 

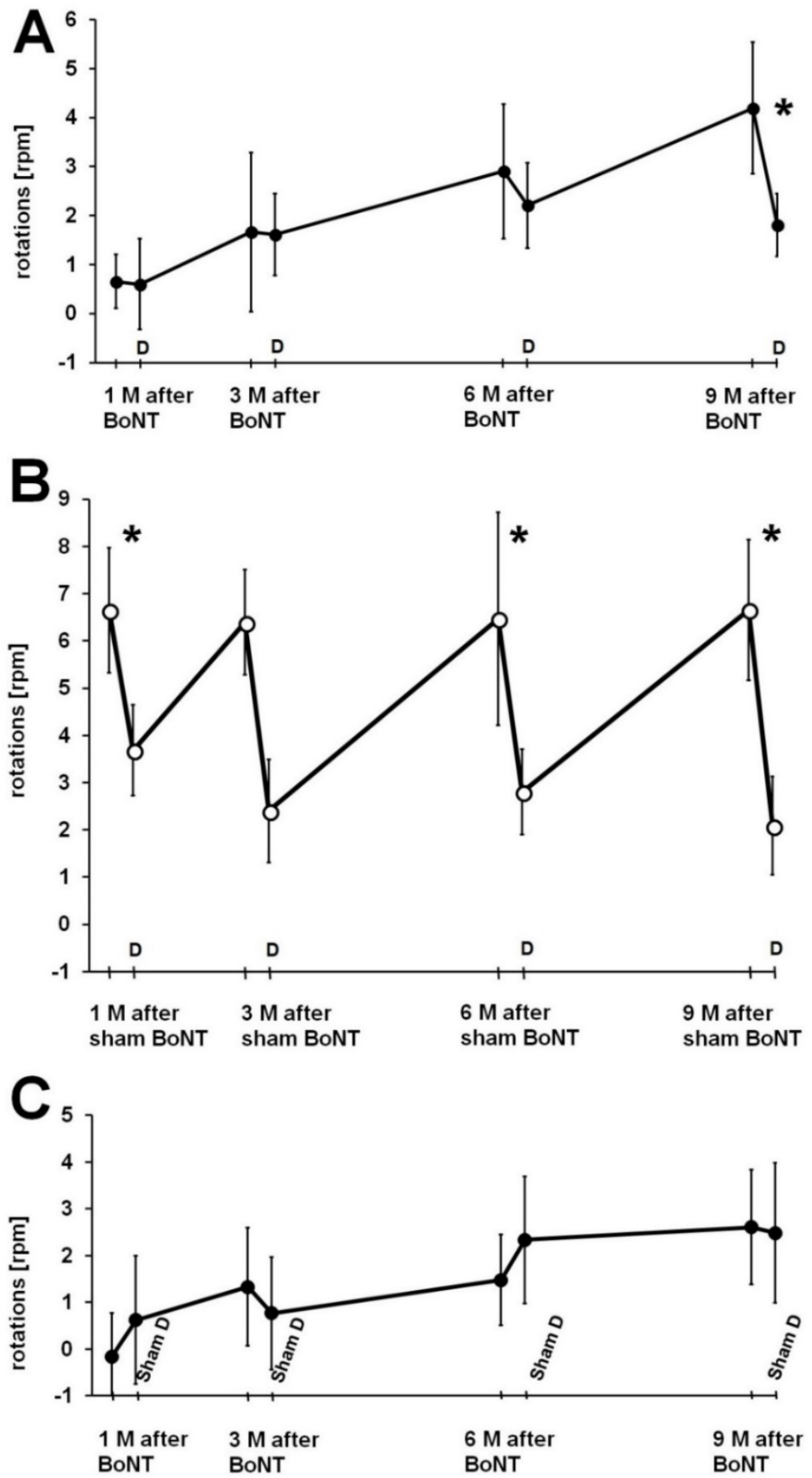

Figure 10. (A,B) Hemi-PD rats treated with intrastriatal BoNT-A (black dots) or vehicle (light dots) underwent repetitively apomorphine-induced rotation tests, before and 1 to 9 months after BoNT-A (A) or sham BoNT-A (B). In the second apomorphine-induced rotation test, under the influence of donepezil injected $1 \mathrm{~h}$ ahead, rotation rates were unchanged in the BoNT-A group (A) but were significantly increased in the sham BoNT-A group up to 9 months (B). Sham donepezil injections $1 \mathrm{~h}$ prior to the second apomorphine-induced rotation tests in BoNT-A-treated hemi-PD rats did not influence their rotational behavior $(\mathbf{C})$. Asterisks indicate significant differences $\left({ }^{*} p<0.05\right)$. Data are represented as mean \pm SEM. 


\section{Discussion}

Injection of $1 \mathrm{ng}$ BoNT-A into the striatum of hemi-PD rats abolishes apomorphine-induced rotations for at least 3 months [12-17]. Thereafter, the apomorphine-induced rotation rate reverses [12-14,38]. Analogous to clinical practice in the use of BoNT-A, we evaluated the effect of repetitive BoNT-A injections (1 and 7 months after 6-OHDA) in the hemi-PD rat model using a battery of tests, including apomorphine-induced rotations and spontaneous behavior tests.

In the striatum, BoNT-A is thought to act in two main directions: ACh release of the tonically active cholinergic interneurons is blocked [1,4,5]; and the concentrations of the dopamine $\mathrm{D}_{2}$ receptor is reduced as shown in hemi-PD rats with $\mathrm{D}_{2}$ receptor upregulation, as in BoNT-A-injected normal rats $[38,39]$.

\subsection{Repetitive Intrastriatal BoNT-A Injection in Hemi-PD Rats}

\subsubsection{Body Weight}

Neither first nor second intrastriatal BoNT-A injections significantly influenced the body weight of the rats. Even 12 months after the second BoNT-A application, body weights of BoNT-A- (551 \pm 11 g; mean \pm SEM) or sham-injected rats $(581 \pm 14 \mathrm{~g})$ did not differ significantly. Thus, repetitive intrastriatal BoNT-A had no negative effect on the health of the rats, being in line with unaltered measures after the single BoNT-A application [12,39].

\subsubsection{Apomorphine-Induced Rotation Test}

It was shown that intrastriatal injection of $1 \mathrm{ng}$ BoNT-A in hemi-PD rats ameliorated apomorphine-induced rotations for at least 3 months, and during 12 months after BoNT-A treatment, hemi-PD rats showed a gradual recurrence of the apomorphine-induced rotation rate [12-17]. We demonstrated that repetitive intrastriatal injections of BoNT-A in hemi-PD rats were well tolerated, and the second injection had an effect significantly exceeding the behavioral outcome of the first injection. The second BoNT-A injection led to a more distinct reduction of the apomorphine-induced rotation rate after 1 month: Rotation rate 1 month after first BoNT-A was $2.27 \pm 0.86 \mathrm{rpm}$, and $0.17 \pm 0.58 \mathrm{rpm}$ (mean $\pm \mathrm{SEM}$ ) after second BoNT-A. The time dependent slope of apomorphine-induced rotations was flatter after the second BoNT-A injection: Rotation rate 3 months after first BoNT-A was $4.44 \pm 0.86 \mathrm{rpm}$, and $1.32 \pm 1.06 \mathrm{rpm}$ after second BoNT-A. Rotation rate 6 months after first BoNT-A was $6.85 \pm 1.05 \mathrm{rpm}$, and $2.20 \pm 0.91 \mathrm{rpm}$ after second BoNT-A. The 3 months effect of the first BoNT-A injection equaled that of the 12 months effect of the second BoNT-A application (5.08 $\pm 0.54 \mathrm{rpm})$. These results suggested that although 6 months after the first BoNT-A injection, the rotation rate retoured to the pre-BoNT-A value ( 6 months after first BoNT-A $=6.85 \pm 1.05 \mathrm{rpm}$, pre-BoNT-A = $5.75 \pm 1.25 \mathrm{rpm}$ ), a residual impact of the first BoNT-A application seemingly persisted.

Our results concerning the more profound effect of the second intrastriatal BoNT-A injection, were in line with the prolongation of the therapeutic intervals observed following intramuscular BoNT-A injections. Rogozhin et al. [40] demonstrated in the mouse epitrochleoanconeus muscle that after repeated BoNT-A administrations, the functional recovery of neuromuscular transmission occurred slower than after a single BoNT-A injection. After a single BoNT-A injection, quantal ACh release from motor nerve terminals reached $50 \%$ of control about 6 weeks after injection; however, after repetitive BoNT-A this level was reached about 11 to 15 weeks after the last injection. Accordingly, striking structural abnormalities of neuromuscular junctions and intramuscular nerves were more pronounced after repetitive injections. Moreover, in human therapeutic BoNT-A application, more distinct and longer lasting effects, resulting in an increase in the mean duration of efficacy with the number of injections are well known [41-45].

We suppose that 6 months after the first intrastriatal BoNT-A injection, morphological and/or physiological parameters had not fully recovered, so that the second BoNT-A application caused 
a more distinct and cumulative effect, seen in the longer and more pronounced reduction of the apomorphine-induced turning rate. This phenomenon is seemingly a specific BoNT-A effect, as the apomorphine-induced rotation rate was not dependent on the time after 6-OHDA lesion, and even not influenced by sham injection experiments [38].

\subsubsection{Spontaneous Motor Tests}

Unilateral right side 6-OHDA lesion induced marked and long-lasting stepping deficits with the left forepaw (contralateral to lesion), in both forehand and backhand directions. Neither the first nor the second ipsilateral intrastriatal BoNT-A injection changed the impairments seen in hemi-PD rats. The same was true for sensorimotor integration behavior. In the corridor task, right side hemi-PD resulted in a massive neglect of the left corridor side. The first, as well as the second ipsilateral intrastriatal BoNT-A injection, did not improve contralateral sensorimotor integration significantly.

The outcomes of both behavioral tests reflected the motor initiation deficits of the forelimb, depending on contralateral striatal DA depletion [46-51]. DA deprivation of the striatum leads to increased GABAergic MSN projection to the EGP, which results in a disinhibition of the spontaneously active STh. As a result, a more intensely firing IGP inhibits VL. Finally, the inhibited VL neurons do not adequately activate the premotor cortex, which in turn reduces initiation of movements of the contralateral body via its crossed motor efferents [52-55]. Intrastriatal ipsilateral BoNT-A injection of $1 \mathrm{ng}$ BoNT-A did not change the impairments seen in hemi-PD rats. Probably, the BoNT-A-induced changes in the DA deprived CPu concerning extracellular ACh content [56-58], and receptors of DA and others transmitters [59-61] were not adequate to improve spontaneous motor behavior. The degree of bradykinesia is associated with the degree of depletion of DA neurons [62,63]. Only animals with more than $80 \%$ striatal DA depletion exhibited similar stepping deficits [62,64-66], whilst animals with less depletion did not $[33,67]$. As in hemi-PD rats, the DA deprivation was almost complete [68-71], and consequently, not influenced by BoNT-A applications. It is not surprising that stepping behavior and sensorimotor integration were changed, neither by the first nor the second ipsilateral intrastriatal BoNT-A application.

\subsection{Influence of Application of $2 \mathrm{mg} \mathrm{kg}^{-1} \mathrm{BW}$ Donepezil Prior to Apomorphine-Induced Rotation Test}

Hemi-PD rats treated intrastriatally with BoNT-A and injected with $2 \mathrm{mg} \mathrm{kg}^{-1} \mathrm{BW}$ donepezil $24 \mathrm{~h}$ prior an apomorphine-induced rotation test, showed a significant increase of their turning rate, compared to a rotation test $72 \mathrm{~h}$ before. This seemingly proved our working hypothesis that the BoNT-A-induced reduction of apomorphine-induced rotation rate of hemi-PD rats was due to a reduction of the striatal ACh content. However, in sham BoNT-A-treated hemi-PD rats, we found comparable results. Moreover, time matched sham donepezil-injected BoNT-A-treated hemi-PD rats showed a significantly increase in turning rate, respectively. Therefore, we concluded that the similar increases of the rotation rate were not due to specific donepezil-induced increase of extracellular ACh content in the striatum. According to the microdialysis, studying ACh in the cortex and hippocampus of freely-moving rats following i.p. injection of $4 \mu \mathrm{mol} \mathrm{kg}{ }^{-1}$ donepezil, extracellular ACh concentrations steeply increased, and showed maximal values 1 to $2 \mathrm{~h}$ after injection and reached baseline levels again after about 4 to $5 \mathrm{~h}$ [72-74]. Thus, apomorphine injections at an interval of $72 \mathrm{~h}$ were seemingly unaffected by donepezil, but could tentatively have caused a behavioral sensitization, discussed in repetitive apomorphine applications [75,76].

Remarkably, an injection of $2 \mathrm{mg} \mathrm{kg}^{-1} \mathrm{BW}$ donepezil $1 \mathrm{~h}$ prior to an apomorphine-induced rotation test, in contrast to a donepezil injection $24 \mathrm{~h}$ prior to a rotation test, leads to a significant reduction of the turning rate in sham BoNT-A-treated rats, and to a tendential reduction of the turning rate in BoNT-A-treated rats. Obviously, the effect of donepezil in rats is limited to some hours after its systemic application, because we registered strong effects on the apomorphine-induced rotation behavior $1 \mathrm{~h}$ after injection, but we saw no specific alterations $24 \mathrm{~h}$ after application. So our results remain in line with those reports postulating a $t_{1 / 2}$ of donepezil of few hours [26-29], and shown by 
others [72-74,77]. Contradicting our working hypothesis, the application of donepezil did not lead to a jump of the turning rate in BoNT-A-treated hemi-PD rats. We suppose that this is due to the systemic action of donepezil. Babiloni et al. (2014) investigated the effect of donepezil on EEG markers and motor activity in mice during short post-administration periods up to $3 \mathrm{~h}$. Donepezil normalized motor activity, compared to vehicle-induced increased motor activity [78]. Comparable results were seen in a traumatic brain injury model, where Shaw et al. (2013) subsequent to daily donepezil injection (19 days) did not find motor improvement, but stated significantly impaired beam-balance time and beam-walk time at the dosage used in our experiments [79].

Although donepezil was shown as beneficial with respect to cognition in mild to moderate dementia [80-83], and also moderate dementia with Parkinson's disease, donepezil therapy did not change motor PD symptoms $[84,85]$. Furthermore, donepezil treated dementia with Lewy body, without relevant worsening of extrapyramidal symptoms [86]. However, others stated that donepezil treatment could cause adverse motor effects in a subset of patients with parkinsonian dementia [87-90]; worsened activities of daily living mobility in patients with progressive supranuclear palsy [91]; and deteriorated motor behavior in patients with dystonic reactions [92].

It can be speculated that the reductions of apomorphine-induced rotations, following $1 \mathrm{~h}$ after donepezil, were not caused by an increase of extracellular ACh in the striatum, but by a general depression of the rats' motor activity. The donepezil-related reduction in motor activity was measured in the sham-treated hemi-PD rats, as a reduction in apomorphine-induced rotations (Figure 10B). Seemingly, no significant donepezil-induced (Figure 10A) or sham donepezil-induced (Figure 10C) reductions in motor activity were measured in the BoNT-A-treated hemi-PD rats, as those rats performed fewer rotations per se.

We conclude, that the systemic administration of donepezil, irrespective of the time prior to an apomorphine-induced rotation test, was not a qualified method to prove the ACh dependence of the effect of intrastriatal injection BoNT-A. Application of donepezil $24 \mathrm{~h}$ ahead of apomorphine had no specific effect, as the temporal increase of extracellular ACh in the brain was already abrogated. Application of donepezil $1 \mathrm{~h}$ before apomorphine likely did not have the hypothetically expected effect, i.e., reversing the BoNT-A-induced reduction of apomorphine-induced rotation behavior, caused by the increase of extracellular $\mathrm{ACh}$, as the general motor-depressive effect of donepezil exceeded that of the increase of extracellular ACh in the striatum.

\section{Conclusions}

Firstly, data showed that repeated intrastriatal BoNT-A injections in the hemi-PD rat model were possible and well tolerated. In hemi-PD rats, the second intrastriatal BoNT-A injection had a more intense and longer lasting effect on the reduction of apomorphine-induced rotations, but like the first one, it did not affect forelimb akinesia and lateralized sensorimotor integration. Secondly, systemic donepezil injection prior to testing the apomorphine-induced rotation behavior is not qualified to prove the dependency of striatal extracellular ACh content for turning rate reductions after BoNT-A treatment.

These different effects of BoNT-A application suggest that intrastriatally applied BoNT-A acts both as an inhibitor of $\mathrm{ACh}$ release and influences transmitter receptors, especially $\mathrm{D}_{2}$ receptor expression, and thereby, affects the basal ganglia circuitries. Therefore, the evaluation of receptor densities of all important striatal transmitters is the subject of ongoing studies of our group.

\section{Materials and Methods}

\subsection{Animals}

All experiments were started with 2.5 months old, male Wistar rats (strain Crl:WI BR, Charles River Wiga, Sulzfeld, Germany) weighing 295-305 g. Animals were housed in standard cages at $22{ }^{\circ} \mathrm{C} \pm 2{ }^{\circ} \mathrm{C}$ under a $12 \mathrm{~h}$ light/dark cycle, with free access to water and food. All procedures used in 
the present study complied with the guidelines on animal care. The experiments were approved by the local Animal Research Committee of the state of Mecklenburg-Western Pomerania (LALLF M-V 7221.3-1.1-003/13 from 26 April 2013.

\subsection{Induction of Hemiparkinsonism}

All surgeries were carried out under aseptic conditions and deep anesthesia (50 $\left.\mathrm{mg} \mathrm{kg}^{-1} \mathrm{BW}\right)$ ketamine and $4 \mathrm{mg} \mathrm{kg}^{-1} \mathrm{BW}$ xylazine). To induce an experimental hemi-PD syndrome, a unilateral injection of $24 \mu \mathrm{g}$ 6-OHDA dissolved in $4 \mu \mathrm{L} 0.1 \mathrm{M}$ citrate buffer was performed into the right medial forebrain bundle (MFB), using a stereotactic frame (Stoelting, Wood Dale, IL, USA). The injection coordinates with reference to bregma were: $\mathrm{AP}=-2.3, \mathrm{~L}=1.5, \mathrm{~V}=-9.0$, as described in Reference [93]. The success of the lesion was verified by measurement of the apomorphine-induced rotation rate [94,95], 4 weeks after 6 -OHDA injection. Rats $(n=45)$ that displayed an apomorphine-induced rotation rate of at least 4 rotations per minute to the left side, were successfully lesioned, indicating unilateral death of about $97 \%$ of the nigrostriatal dopaminergic neurons [95]. Only those rats were used for further experiments.

\subsection{Body Weight}

Body weights were measured at the following time points: 6-OHDA injection, first and second BoNT-A or vehicle injections, as well as at every monitoring point and 12 months after the second BoNT-A or vehicle applications.

\subsection{Injection of BoNT-A into the Striatum}

About 6 weeks after the 6-OHDA injection, the animals underwent a next stereotactic surgery (Figure 2). Either a solution of BoNT-A dissolved in phosphate-buffered saline supplemented with 0.1\% bovine serum (prepared from BoNT-A powder, Lot No. 13028A1A; List, Campbell, CA, USA; purchased via Quadratech, Surrey, UK) or vehicle (sham BoNT-A) solution was injected into the right $\mathrm{CPu}$ at two sites $[12,14,15]$. Hemi-PD rats were treated with either $1 \mathrm{ng} \operatorname{BoNT}-\mathrm{A}(n=29)$ or vehicle $(n=16)$. The respective coordinates with reference to bregma were: $\mathrm{AP}=+1.3 /-0.4 \mathrm{~mm}$, $\mathrm{L}=2.6 / 3.6 \mathrm{~mm}$ to the right, and $\mathrm{V}=-5.5 \mathrm{~mm}$. Animals received a $2 \times 1 \mu \mathrm{L}$ BoNT-A solution containing a total of $1 \mathrm{ng}$ BoNT-A or vehicle solution. Animals for the repetitive BoNT-A injection experiment underwent a second BoNT-A or a sham injection with vehicle solution, 6 months after the first one, respectively (Figure 2).

\subsection{Apomorphine-Induced Rotation Test}

The rate of apomorphine-induced rotations, served as a measure for the extent of the basal ganglia circuit disturbance by the unilateral lesion of the SNpc [94,95].

The apomorphine-induced turning rate was ascertained 4 weeks after the 6-OHDA lesion, and 1, 3, and 6 months after the first BoNT-A injection, as well as 1, 3, 6, 9, and 12 months after the second BoNT-A treatment. Two experimental groups were studied: hemi-PD rats treated with BoNT-A $(n=16)$, and hemi-PD rats injected with vehicle solution $(n=8)$ (Figure 2$)$.

Apomorphine was injected s. c. $\left(0.25 \mathrm{mg} \mathrm{kg}^{-1}\right)$ and the animals' turns registered on a self-constructed automated rotometer device over $40 \mathrm{~min}$. In right-sided hemi-PD rats, the apomorphine-induced complete anti-clockwise $360^{\circ}$ turns were expressed as positive values (Figures 4, 8 and 10).

\subsection{Spontaneous Motor Tests}

Stepping test and corridor task were performed before 6-OHDA lesion, 4 weeks thereafter, and 1, 3 , and 6 months after the first ipsilateral intrastriatal injection of BoNT-A or sham BoNT-A; and 1, 3, 6, 9, and 12 months after the second BoNT-A or vehicle injection (Figure 2). 


\subsubsection{Adjusting Steps}

Before evaluating adjusting steps, rats were handled by the experimenter during 3 days to adapt to the test procedure $[33,96,97]$. Tests were performed twice per day on 3 successive days. Briefly, the rat was held with one hand softly blocking both its hind limbs and the restrained forelimb, with the unrestrained forepaw touching the table. The rat was moved slowly sideways across the table (90 $\mathrm{cm}$ in $5 \mathrm{~s}$ ) and the number of adjusting steps of the unrestrained left or right forelimb was counted, whilst moving in the forehand and backhand directions. Subsequently, the forehand and backhand steps of left and right paws were evaluated using the video recorded sessions, which allowed counting of the number of adjusting steps by an investigator blinded to the state of the rats.

\subsubsection{Corridor Task}

Lateralized response selection was examined using the version, according to Grealish et al. [98]. Prior to testing rats were food restricted for 3 days, and maintained at about $90 \%$ of free-feeding BW during habituation and testing, as described in Reference [99]. Rats were adapted to the self-constructed alleyway ( $240 \mathrm{~cm}$ long $\times 7 \mathrm{~cm}$ wide $\times 23 \mathrm{~cm}$ deep) for 10 min each on 2 successive days, with some scattered sugar pellets (Ain-76A Rodent Tablet $20 \mathrm{mg}$ TestDiet, Richmond, IN, USA) along the floor of the corridor. Each day, the animals started from different ends of the corridor. For final testing, on day 1 , rats were first placed in an identical but empty corridor for $5 \mathrm{~min}$ for adaptation, and then to the end of the testing corridor. In the testing corridor, bowls $(2 \mathrm{~cm}$ in diameter, distance between the bowls $15 \mathrm{~cm}$ ) were placed on the left and right sides, containing 5 pellets each. Rats were allowed for $5 \mathrm{~min}$ to retrieve pellets from either side of their body, as detailed in References [50,100]. The retrievals of the right side (ipsilateral) and left side (contralateral) were counted, and the data expressed as the percentage of left- or right-side retrievals on the total number of retrievals. The side is defined according to the rat's body axis. A "retrieval" involved a nose poke into a bowl, whether or not pellets were taken from it, as outlined in References [98,101,102].

\subsection{Donepezil Modifying Apomorphine-Induced Rotations}

In different experiments the possible effect of donepezil on apomorphine-induced rotation rates was evaluated. Hemi-PD rats intrastriatally injected with BoNT-A (1 ng) or sham BoNT-A were twice tested for apomorphine-induced rotations, at an interval of $72 \mathrm{~h}$. At $24 \mathrm{~h}$ or $1 \mathrm{~h}$ prior to the second test for apomorphine-induced rotations, donepezil $\left(2 \mathrm{mg} \mathrm{kg}^{-1} \mathrm{BW}\right)$ or sham donepezil $(0.9 \% \mathrm{NaCl})$ was injected i.p. (Figures 8 and 10).

Thus, a total of 7 groups were tested: (i) hemi-PD + BoNT-A $+24 \mathrm{~h}$ donepezil $(n=15)$; (ii) hemi-PD + sham BoNT-A + 24 h donepezil $(n=9)$; (iii) hemi-PD + BoNT-A + 24 h sham donepezil ( $n=14)$; (iv) hemi-PD + sham BoNT-A + 24 h sham donepezil $(n=7) ;(v)$ hemi-PD + BoNT-A + $1 \mathrm{~h}$ donepezil $(n=6)$; (vi) hemi-PD + sham BoNT-A +1 h donepezil $(n=6)$; and (vii) hemi-PD + BoNT-A $+1 \mathrm{~h}$ sham donepezil $(n=6)$ - (not done: hemi-PD + sham BoNT-A $+1 \mathrm{~h}$ sham donepezil). Groups i-iv were tested 1 to 4 months after BoNT-A or sham BoNT-A, and groups v-vii 1 to 12 months after BoNT-A or sham BoNT-A.

\subsection{Data Analysis}

The results were presented as means \pm SEM. Computations and statistics of donepezil modifying apomorphine-induced rotations were performed with Excel ${ }^{\circledR}$. For comparison of rotation rates and slopes of rotation rates between two animal groups at the same monitoring point, the unpaired Student's $t$-Test was performed. For investigation of rotation rates and slopes of the rotation rate of one animal group at different monitoring points, the paired Student's $t$-Test was performed. In all cases, $p$ values $\leq 0.05$ were considered significant and $p$ values $<0.01$ were considered highly significant.

Data of body weights and spontaneous motor tests, i.e., stepping test and corridor task, were subjected to two-way ANOVA using SigmaPlot 11 Software (Systat Software, Inc., San Jose, 
CA 95110, USA). The Holm-Sidak approach was used for adjustment for multiple testing, for post hoc comparisons. A critical value for significance of $p \leq 0.05$ was used.

Author Contributions: Conceptualization, A.H., A.W., and V.A.; Formal analysis, C.H.; Funding acquisition, A.H. and A.W.; Investigation, A.H., A.W., and V.A.; Methodology, V.A.; Supervision, A.H. and A.W.; Visualization, A.H. and C.H.; Writing-original draft, A.H., C.H., A.W., and V.A.

Funding: Rostock University Medical Center internal funding FORUN 889005 and 889014.

Acknowledgments: The technical assistance of Susann Lehmann and Frauke Winzer is gratefully acknowledged. Conflicts of Interest: The authors declare no conflict of interest regarding the material in the manuscript.

$\begin{array}{ll}\text { Abbreviations } \\ \text { 6-OHDA } & \text { 6-hydroxydopamine } \\ \text { ACh } & \text { acetylcholine } \\ \text { AChE } & \text { acetylcholinesterase } \\ \text { BoNT-A } & \text { botulinum neurotoxin-A } \\ \text { BW } & \text { body weight } \\ \text { CPu } & \text { caudate-putamen (striatum) } \\ \text { DA } & \text { dopamine } \\ \text { D } & \text { dopamine } \text { D }_{2} \text { receptor } \\ \text { EGP (=LGP) } & \text { external (lateral) globus pallidus } \\ \text { GABA } & \text { gamma-aminobutyric acid } \\ \text { hemi-PD } & \text { hemiparkinsonian } \\ \text { IGP (=MGP) } & \text { internal (medial) globus pallidus } \\ \text { M } & \text { slope/drawdown } \\ \text { MFB } & \text { medial forebrain bundle } \\ \text { MSN } & \text { medium spiny neuron } \\ \text { PD } & \text { Parkinson's disease } \\ \text { PPN } & \text { pedunculopontine nucleus } \\ \text { RPM/d } & \text { (revolutions per minute)/day } \\ \text { SNAP-25 } & \text { synaptosomal-associated protein-25 } \\ \text { SNARE } & \text { N-ethylmaleimide-sensitive-factor attachment receptor } \\ \text { SNpc } & \text { substantia nigra pars compacta } \\ \text { STh } & \text { subthalamic nucleus } \\ \text { VL } & \text { ventrolateral thalamic nucleus }\end{array}$

\section{References}

1. Day, M.; Wang, Z.; Ding, J.; An, X.; Ingham, C.A.; Shering, A.F.; Wokosin, D.; Ilijic, E.; Sun, Z.; Sampson, A.R.; et al. Selective elimination of glutamatergic synapses on striatopallidal neurons in Parkinson disease models. Nat. Neurosci. 2006, 9, 251-259. [CrossRef] [PubMed]

2. Duvoisin, R.C. Cholinergic-Anticholinergic Antagonism in Parkinsonism. Arch. Neurol. 1967, 17, $124-136$. [CrossRef] [PubMed]

3. Pisani, A.; Bernardi, G.; Ding, J.; Surmeier, D.J. Re-emergence of striatal cholinergic interneurons in movement disorders. Trends Neurosci. 2007, 30, 545-553. [CrossRef] [PubMed]

4. Obeso, J.Á.; Marin, C.; Rodriguez-Oroz, C.; Blesa, J.; Benitez-Temiño, B.; Mena-Segovia, J.; Rodríguez, M.; Olanow, C.W. The basal ganglia in Parkinson's disease: Current concepts and unexplained observations. Ann. Neurol. 2008, 64, S30-S46. [CrossRef] [PubMed]

5. Obeso, J.Á.; Rodríguez-Oroz, M.C.; Benitez-Temino, B.; Blesa, F.J.; Guridi, J.; Marin, C.; Rodriguez, M. Functional organization of the basal ganglia: Therapeutic implications for Parkinson's disease. Mov. Disord. 2008, 23, S548-S559. [CrossRef] [PubMed]

6. Bohnen, N.I.; Albin, R.L. The cholinergic system and Parkinson disease. Behav. Brain Res. 2011, 221, $564-573$. [CrossRef] [PubMed]

7. Clarke, C.E. Medical Management of Parkinson's Disease. J. Neurol. Neurosurg. Psychiatry 2002, 72, i22-i27. [CrossRef] [PubMed] 
8. Connolly, B.S.; Lang, A.E. Pharmacological treatment of Parkinson disease: A review. JAMA 2014, 311, 1670-1683. [CrossRef] [PubMed]

9. Whitney, C.M. Medications for Parkinson's disease. Neurologist 2007, 13, 387-388. [CrossRef] [PubMed]

10. Montecucco, C.; Schiavo, G. Structure and Function of Tetanus and Botulinum Neurotoxins. Q. Rev. Biophys. 1995, 28, 423-472. [CrossRef] [PubMed]

11. Coffeld, J.A.; Considine, R.V.; Simpson, L.L. Clostridial neurotoxins in the age of molecular medicine. Trends Microbiol. 1994, 2, 67-69. [CrossRef]

12. Wree, A.; Mix, E.; Hawlitschka, A.; Antipova, V.; Witt, M.; Schmitt, O.; Benecke, R. Intrastriatal botulinum toxin abolishes pathologic rotational behaviour and induces axonal varicosities in the 6-OHDA rat model of Parkinson's disease. Neurobiol. Dis. 2011, 41, 291-298. [CrossRef] [PubMed]

13. Antipova, V.; Hawlitschka, A.; Mix, E.; Schmitt, O.; Dräger, D.; Benecke, R.; Wree, A. Behavioral and structural effects of unilateral intrastriatal injections of botulinum neurotoxin a in the rat model of Parkinson's disease. J. Neurosci. Res. 2013, 91, 838-847. [CrossRef] [PubMed]

14. Antipova, V.A.; Holzmann, C.; Schmitt, O.; Wree, A.; Hawlitschka, A. Botulinum Neurotoxin A Injected Ipsilaterally or Contralaterally into the Striatum in the Rat 6-OHDA Model of Unilateral Parkinson's Disease Differently Affects Behavior. Front. Behav. Neurosci. 2017, 11, 119. [CrossRef] [PubMed]

15. Hawlitschka, A.; Antipova, V.; Schmitt, O.; Witt, M.; Benecke, R.; Mix, E.; Wree, A. Intracerebrally applied botulinum neurotoxin in experimental neuroscience. Curr. Pharm. Biotechnol. 2013, 14, 124-130. [CrossRef] [PubMed]

16. Holzmann, C.; Dräger, D.; Mix, E.; Hawlitschka, A.; Antipova, V.; Benecke, R.; Wree, A. Effects of intrastriatal botulinum neurotoxin A on the behavior of Wistar rats. Behav. Brain Res. 2012, 234, 107-116. [CrossRef] [PubMed]

17. Mehlan, J.; Brosig, H.; Schmitt, O.; Mix, E.; Wree, A.; Hawlitschka, A. Intrastriatal injection of botulinum neurotoxin-A is not cytotoxic in rat brain-A histological and stereological analysis. Brain Res. 2016, 1630, 18-24. [CrossRef] [PubMed]

18. Chen, S. Clinical uses of botulinum neurotoxins: Current indications, limitations and future developments. Toxins 2012, 4, 913-939. [CrossRef] [PubMed]

19. Orsini, M.; Leite, M.A.A.; Chung, T.M.; Bocca, W.; de Souza, J.A.; de Souza, O.G.; Moreira, R.P.; Bastos, V.H.; Teixeira, S.; Oliveira, A.B.; et al. Botulinum neurotoxin type A in neurology: Update. Neurol. Int. 2015, 7, 79-84. [CrossRef] [PubMed]

20. Tiseo, P.J.; Foley, K.; Friedhoff, L.T. An evaluation of the pharmacokinetics of donepezil $\mathrm{HCl}$ in patients with moderately to severely impaired renal function. Br. J. Clin. Pharmacol. 1998, 46 (Suppl. 1), 56-60. [CrossRef] [PubMed]

21. Mihara, M.; Ohnishi, A.; Tomono, Y.; Hasegawa, J.; Shimamura, Y.; Yamazaki, K.; Morishita, N. Pharmacokinetics of E2020, a new compound for Alzheimer's disease, in healthy male volunteers. Int. J. Clin. Pharmacol. Ther. Toxicol. 1993, 31, 223-229. [PubMed]

22. Ohnishi, A.; Mihara, M.; Kamakura, H.; Tomono, Y.; Hasegawa, J.; Yamazaki, K.; Morishita, N.; Tanaka, T. Comparison of the pharmacokinetics of E2020, a new compound for Alzheimer's disease, in healthy young and elderly subjects. J. Clin. Pharmacol. 1993, 33, 1086-1091. [CrossRef] [PubMed]

23. Snape, M.F.; Misra, A.; Murray, T.K.; De Souza, R.J.; Williams, J.L.; Cross, A.J.; Green, A.R. A comparative study in rats of the in vitro and in vivo pharmacology of the acetylcholinesterase inhibitors tacrine, donepezil and NXX-066. Neuropharmacology 1999, 38, 181-193. [CrossRef]

24. Barnes, C.A.; Meltzer, J.; Houston, F.; Orr, G.; McGann, K.; Wenk, G.L. Chronic treatment of old rats with donepezil or galantamine: Effects on memory, hippocampal plasticity and nicotinic receptors. Neuroscience 2000, 99, 17-23. [CrossRef]

25. Mumenthaler, M.S.; Yesavage, J.A.; Taylor, J.L.; O’Hara, R.; Friedman, L.; Lee, H.; Kraemer, H.C. Psychoactive drugs and pilot performance: A comparison of nicotine, donepezil, and alcohol effects. Neuropsychopharmacology 2003, 28, 1366-1373. [CrossRef] [PubMed]

26. Geerts, H.; Guillaumat, P.O.; Grantham, C.; Bode, W.; Anciaux, K.; Sachak, S. Brain levels and acetylcholinesterase inhibition with galantamine and donepezil in rats, mice, and rabbits. Brain Res. 2005, 1033, 186-193. [CrossRef] [PubMed] 
27. Goh, C.W.; Aw, C.C.; Lee, J.H.; Chen, C.P.; Browne, E.R. Pharmacokinetic and pharmacodynamic properties of cholinesterase inhibitors donepezil, tacrine, and galantamine in aged and young lister hooded rats. Drug Metab. Dispos. 2011, 39, 402-411. [CrossRef] [PubMed]

28. Nirogi, R.; Bhyrapuneni, G.; Kandikere, V.; Benade, V.; Muddana, N.; Saralaya, R.; Irappanavar, S.; Ponnamaneni, R.; Mukkanti, K. Concurrent administration of atypical antipsychotics and donepezil: Drug interaction study in rats. Eur. J. Drug Metab. Pharmacokinet. 2012, 37, 155-161. [CrossRef] [PubMed]

29. Matsui, K.; Mishima, M.; Nagai, Y.; Yuzuriha, T.; Yoshimura, T. Absorption, distribution, metabolism, and excretion of donepezil (Aricept) after a single oral administration to Rat. Drug Metab. Dispos. 1999, 27, 1406-1414. [PubMed]

30. Kirik, D.; Georgievska, B.; Burger, C.; Winkler, C.; Muzyczka, N.; Mandel, R.J.; Björklund, A. Reversal of motor impairments in parkinsonian rats by continuous intrastriatal delivery of L-dopa using rAAV-mediated gene transfer. Proc. Natl. Acad. Sci. USA 2002, 99, 4708-4713. [CrossRef] [PubMed]

31. Kirik, D.; Rosenblad, C.; Bjorklund, A. Preservation of a functional nigrostriatal dopamine pathway by GDNF in the intrastriatal 6-OHDA lesion model depends on the site of administration of the trophic factor. Eur. J. Neurosci. 2000, 12, 3871-3882. [CrossRef] [PubMed]

32. Kirik, D.; Rosenblad, C.; Bjorklund, A.; Mandel, R.J. Long-term rAAV-mediated gene transfer of GDNF in the rat Parkinson's model: Intrastriatal but not intranigral transduction promotes functional regeneration in the lesioned nigrostriatal system. J. Neurosci. 2000, 20, 4686-4700. [CrossRef] [PubMed]

33. Olsson, M.; Nikkhah, G.; Bentlage, C.; Björklund, A. Forelimb akinesia in the rat Parkinson model: Differential effects of dopamine agonists and nigral transplants as assessed by a new stepping test. J. Neurosci. 1995, 15, 3863-3875. [CrossRef] [PubMed]

34. Dronfield, S.; Egan, K.; Marsden, C.A.; Green, A.R. Comparison of donepezil-, tacrine-, rivastigmine-and metrifonateinduced central and peripheral cholinergically mediated responses in the rat. J. Psychopharmacol. 2000, 14, 275-279. [CrossRef] [PubMed]

35. Haug, K.H.; Bogen, I.L.; Osmundsen, H.; Walaas, I.; Fonnum, F. Effects on cholinergic markers in rat brain and blood after short and prolonged administration of donepezil. Neurochem. Res. 2005, 30, 1511-1520. [CrossRef] [PubMed]

36. Hatip-Al-Khatib, I.; Takashi, A.; Egashira, N.; Iwasaki, K.; Fujiwara, M. Comparison of the effect of TAK-147 (zanapezil) and E-2020 (donepezil) on extracellular acetylcholine level and blood flow in the ventral hippocampus of freely moving rats. Brain Res. 2004, 1012, 169-176. [CrossRef] [PubMed]

37. Kosasa, T.; Kuriya, Y.; Yamanishi, Y. Effect of donepezil hydrochloride (E2020) on extracellular acetylcholine concentration in the cerebral cortex of rats. Jpn. J. Pharmacol. 1999, 81, 216-222. [CrossRef] [PubMed]

38. Mann, T.; Zilles, K.; Dikow, H.; Hellfritsch, A.; Cremer, M.; Piel, M.; Rösch, F.; Hawlitschka, A.; Schmitt, O.; Wree, A. Dopamine, Noradrenaline and Serotonin Receptor Densities in the Striatum of Hemiparkinsonian Rats following Botulinum Neurotoxin-A Injection. Neuroscience 2018, 374, 187-204. [CrossRef] [PubMed]

39. Wedekind, F.; Oskamp, A.; Lang, M.; Hawlitschka, A.; Zilles, K.; Wree, A.; Bauer, A. Intrastriatal administration of botulinum neurotoxin A normalizes striatal D2R binding and reduces striatal D1R binding in male hemiparkinsonian rats. J. Neurosci. Res. 2017. [CrossRef]

40. Rogozhin, A.A.; Pang, K.K.; Bukharaeva, E.; Young, C.; Slater, C.R. Recovery of mouse neuromuscular junctions from single and repeated injections of botulinum neurotoxin A. J. Physiol. 2008, 586, 3163-3182. [CrossRef] [PubMed]

41. Şen, A.; Arpaci, B. Effects of Repeated Botulinum Toxin Treatment for Sialorrhea in Patients with Parkinson's disease. Noro Psikiyatr. Ars. 2015, 52, 69-72. [CrossRef] [PubMed]

42. Brashear, A.; Hogan, P.; Wooten-Watts, M.; Marchetti, A.; Magar, R.; Martin, J. Longitudinal assessment of the dose consistency of botulinum toxin type A (BOTOX $\left.{ }^{\circledR}\right)$ for cervical dystonia. Adv. Ther. 2005, 22, 49-55. [CrossRef] [PubMed]

43. Gordon, M.F.; Barron, R. Effectiveness of repeated treatment with botulinum toxin type A across different conditions. South. Med. J. 2006, 99, 853-861. [CrossRef] [PubMed]

44. Colosimo, C.; Tiple, D.; Berardelli, A. Efficacy and safety of long-term botulinum toxin treatment in craniocervical dystonia: A systematic review. Neurotox. Res. 2012, 22, 265-273. [CrossRef] [PubMed]

45. Flynn, T.C. Botulinum toxin: Examining duration of effect in facial aesthetic applications. Am. J. Clin. Dermatol. 2010, 11, 183-199. [CrossRef] [PubMed] 
46. Spirduso, W.W.; Gilliam, P.E.; Schallert, T.; Upchurch, M.; Vaughn, D.M.; Wilcox, R.E. Reactive capacity: A sensitive behavioral marker of movement initiation and nigrostriatal dopamine function. Brain Res. 1985, 335, 45-54. [CrossRef]

47. Miklyaeva, E.I.; Martens, D.J.; Whishaw, I.Q. Impairments and compensatory adjustments in spontaneous movement after unilateral dopamine depletion in rats. Brain Res. 1995, 681, 23-40. [CrossRef]

48. Tillerson, J.L.; Cohen, A.D.; Philhower, J.; Miller, G.W.; Zigmond, M.J.; Schallert, T. Forced limb-use effects on the behavioral and neurochemical effects of 6-hydroxydopamine. J. Neurosci. 2001, 21, 4427-4435. [CrossRef] [PubMed]

49. Cho, J.; Duke, D.; Manzino, L.; Sonsalla, P.K.; West, M.O. Dopamine depletion causes fragmented clustering of neurons in the sensorimotor striatum: Evidence of lasting reorganization of corticostriatal input. J. Comp. Neurol. 2002, 452, 24-37. [CrossRef] [PubMed]

50. Fitzsimmons, D.F.; Moloney, T.C.; Dowd, E. Further validation of the corridor task for assessing deficit and recovery in the hemi-Parkinsonian rat: Restoration of bilateral food retrieval by dopamine receptor agonism. Behav. Brain Res. 2006, 169, 352-355. [CrossRef] [PubMed]

51. Plowman, E.K.; Thomas, N.J.; Kleim, J.A. Striatal dopamine depletion induces forelimb motor impairments and disrupts forelimb movement representations within the motor cortex. J. Parkinsons. Dis. 2011, 1, 93-100. [CrossRef] [PubMed]

52. Oudega, M.; Perez, M.A. Corticospinal reorganization after spinal cord injury. J. Physiol. 2012, 590, 3647-3663. [CrossRef] [PubMed]

53. Takeuchi, Y.; Takahashi, O.; Satoda, T.; Matsushima, R. Long dendrites of the parabrachial nucleus neurons projecting to the amygdala: A horseradish peroxidase and Golgi study in the cat. Exp. Neurol. 1987, 96, 203-207. [CrossRef]

54. Kathe, C.; Hutson, T.H.; Chen, Q.; Shine, H.D.; McMahon, S.B.; Moon, L.D.F. Unilateral pyramidotomy of the corticospinal tract in rats for assessment of neuroplasticity-inducing therapies. J. Vis. Exp. 2014. [CrossRef] [PubMed]

55. Wree, A.; Schmitt, O. Basal Ganglia. In Brain Mapping; Toga, A.W., Ed.; Elsevier Academic: Cambridge, MA, USA, 2015; pp. 217-227, ISBN 9780123973160.

56. Huang, W.; Foster, J.A.; Rogachefsky, A.S. Pharmacology of botulinum toxin. J. Am. Acad. Dermatol. 2000, 43, 249-259. [CrossRef] [PubMed]

57. Rosales, R.L.; Bigalke, H.; Dressler, D. Pharmacology of botulinum toxin: Differences between type A preparations. Eur. J. Neurol. 2006, 13 (Suppl. 1), 2-10. [CrossRef] [PubMed]

58. Nigam, P.K.; Nigam, A. Botulinum toxin. Indian J. Dermatol. 2010, 55, 8-14. [CrossRef] [PubMed]

59. Ashton, A.C.; Dolly, J.O. Characterization of the Inhibitory Action of Botulinum Neurotoxin Type A on the Release of Several Transmitters from Rat Cerebrocortical Synaptosomes. J. Neurochem. 1988, 50, 1808-1816. [CrossRef] [PubMed]

60. Bigalke, H.; Heller, I.; Bizzini, B.; Habermann, E. Tetanus toxin and botulinum A toxin inhibit release and uptake of various transmitters, as studied with particulate preparations from rat brain and spinal cord. Naunyn. Schmiedebergs. Arch. Pharmacol. 1981, 316, 244-251. [CrossRef] [PubMed]

61. Pearce, L.B.; First, E.R.; MacCallum, R.D.; Gupta, A. Pharmacologic characterization of botulinum toxin for basic science and medicine. Toxicon 1997, 35, 1373-1412. [CrossRef]

62. Kirik, D.; Rosenblad, C.; Björklund, A. Characterization of behavioral and neurodegenerative changes following partial lesions of the nigrostriatal dopamine system induced by intrastriatal 6-hydroxydopamine in the rat. Exp. Neurol. 1998, 152, 259-277. [CrossRef] [PubMed]

63. Fang, X.; Sugiyama, K.; Akamine, S.; Namba, H. The stepping test and its learning process in different degrees of unilateral striatal lesions by 6-hydroxydopamine in rats. Neurosci. Res. 2006, 55, 403-409. [CrossRef] [PubMed]

64. Whishaw, I.Q.; Woodward, N.C.; Miklyaeva, E.; Pellis, S.M. Analysis of limb use by control rats and unilateral DA-depleted rats in the Montoya staircase test: Movements, impairments and compensatory strategies. Behav. Brain Res. 1997, 89, 167-177. [CrossRef]

65. Tseng, K.Y.; Kargieman, L.; Gacio, S.; Riquelme, L.A.; Murer, M.G. Consequences of partial and severe dopaminergic lesion on basal ganglia oscillatory activity and akinesia. Eur. J. Neurosci. 2005, 22, 2579-2586. [CrossRef] [PubMed] 
66. Kelsey, J.E.; Mague, S.D.; Pijanowski, R.S.; Harris, R.C.; Kleckner, N.W.; Matthews, R.T. NMDA receptor antagonists ameliorate the stepping deficits produced by unilateral medial forebrain bundle injections of 6-OHDA in rats. Psychopharmacology 2004, 175, 179-188. [CrossRef] [PubMed]

67. Barnéoud, P.; Descombris, E.; Aubin, N.; Abrous, D.N. Evaluation of simple and complex sensorimotor behaviours in rats with a partial lesion of the dopaminergic nigrostriatal system. Eur. J. Neurosci. 2000, 12, 322-336. [CrossRef] [PubMed]

68. Chang, J.W.; Wachtel, S.R.; Young, D.; Kang, U.J. Biochemical and anatomical characterization of forepaw adjusting steps in rat models of Parkinson's disease: Studies on medial forebrain bundle and striatal lesions. Neuroscience 1999, 88, 617-628. [CrossRef]

69. Deumens, R.; Blokland, A.; Prickaerts, J. Modeling Parkinson's disease in rats: An evaluation of 6-OHDA lesions of the nigrostriatal pathway. Exp. Neurol. 2002, 175, 303-317. [CrossRef] [PubMed]

70. Seeger-Armbruster, S.; Von Ameln-Mayerhofer, A. Short- and long-term unilateral 6-hydroxydopamine lesions in rats show different changes in characteristics of spontaneous firing of substantia Nigra pars reticulata neurons. Exp. Brain Res. 2013, 224, 15-24. [CrossRef] [PubMed]

71. Solari, N.; Bonito-Oliva, A.; Fisone, G.; Brambilla, R. Understanding cognitive deficits in Parkinson's disease: Lessons from preclinical animal models. Learn. Mem. 2013, 20, 592-600. [CrossRef] [PubMed]

72. Kawashima, K.; Sato, A.; Yoshizawa, M.; Fujii, T.; Fujimoto, K.; Suzuki, T. Effects of the centrally acting cholinesterase inhibitors tetrahydroaminoacridine and E2020 on the basal concentration of extracellular acetylcholine in the hippocampus of freely moving rats. Naunyn. Schmiedebergs. Arch. Pharmacol. 1994, 350, 523-528. [CrossRef] [PubMed]

73. Liang, Y.Q.; Tang, X.C. Comparative studies of huperzine A, donepezil, and rivastigmine on brain acetylcholine, dopamine, norepinephrine, and 5-hydroxytryptamine levels in freely-moving rats. Acta Pharmacol. Sin. 2006, 27, 1127-1136. [CrossRef] [PubMed]

74. Liang, Y.Q.; Tang, X.C. Comparative effects of huperzine A, donepezil and rivastigmine on cortical acetylcholine level and acetylcholinesterase activity in rats. Neurosci. Lett. 2004, 361, 56-59. [CrossRef] [PubMed]

75. Castro, R.; Abreu, P.; Calzadilla, C.H.; Rodriguez, M. Increased or decreased locomotor response in rats following repeated administration of apomorphine depends on dosage interval. Psychopharmacology 1985, 85, 333-339. [CrossRef] [PubMed]

76. Gancher, S.; Crabbe, J.; Garland, A.; Lea, E.; Woodward, W. Dose- and duration-dependent tolerance to rotational effects of apomorphine in a rat model of Parkinsonism. J. Pharmacol. Exp. Ther. 1995, 272, 275-281. [PubMed]

77. Naik, R.S.; Hartmann, J.; Kiewert, C.; Duysen, E.G.; Lockridge, O.; Klein, J. Effects of rivastigmine and donepezil on brain acetylcholine levels in acetylcholinesterase-deficient mice. J. Pharm. Pharm. Sci. 2009, 12, 79-85. [CrossRef] [PubMed]

78. Babiloni, C.; Del Percio, C.; Infarinato, F.; Messano, F.P.; Forloni, G.; Kelley, J.; Dix, S.; Bordet, R.; Richardson, J.; Limatola, C.; et al. Effects of Donepezil on EEG-EMG markres in wild type (WT) and triple transgenic (TAUPS2APP) mice. Alzheimer's Dement. 2014, 10, P661. [CrossRef]

79. Shaw, K.E.; Bondi, C.O.; Light, S.H.; Massimino, L.A.; McAloon, R.L.; Monaco, C.M.; Kline, A.E. Donepezil Is Ineffective in Promoting Motor and Cognitive Benefits after Controlled Cortical Impact Injury in Male Rats. J. Neurotrauma 2013, 30, 557-564. [CrossRef] [PubMed]

80. Dooley, M.; Lamb, H.M. Donepezil. A review of its use in Alzheimer's disease. Drugs Aging 2000, 16, $199-226$. [CrossRef] [PubMed]

81. Rogers, S.L.; Friedhoff, L.T. The efficacy and safety of donepezil in patients with Alzheimer's disease: Results of a US Multicentre, Randomized, Double-Blind, Placebo-Controlled Trial. The Donepezil Study Group. Dementia 1996, 7, 293-303. [CrossRef] [PubMed]

82. Evans, M.; Ellis, A.; Watson, D.; Chowdhury, T. Sustained cognitive improvement following treatment of Alzheimer's disease with donepezil. Int. J. Geriatr. Psychiatry 2000, 15, 50-53. [CrossRef]

83. Wilkinson, D.; Doody, R.; Helme, R.; Taubman, K.; Mintzer, J.; Kertesz, A.; Pratt, R.D. Donepezil in vascular dementia: A randomized, placebo-controlled study. Neurology 2003, 61, 479-486. [CrossRef] [PubMed]

84. Bohnen, N.; Kaufer, D.; Hendrickson, R.; Ivanco, L.; Moore, R.; DeKosky, S. Effects of donepezil on motor function in patients with Alzheimer disease. J. Clin. Psychopharmacol. 2004, 24, 354-356. [CrossRef] [PubMed] 
85. Ravina, B.; Putt, M.; Siderowf, A.; Farrar, J.T.; Gillespie, M.; Crawley, A.; Fernandez, H.H.; Trieschmann, M.M.; Reichwein, S.; Simuni, T. Donepezil for dementia in Parkinson's disease: A randomised, double blind, placebo controlled, crossover study. J. Neurol. Neurosurg. Psychiatry 2005, 76, 934-939. [CrossRef] [PubMed]

86. Mori, E.; Ikeda, M.; Nakagawa, M.; Miyagishi, H.; Yamaguchi, H.; Kosaka, K. Effects of donepezil on extrapyramidal symptoms in patients with dementia with lewy bodies: A secondary pooled analysis of two randomized-controlled and two open-label long-term extension studies. Dement. Geriatr. Cogn. Disord. 2015, 40, 186-198. [CrossRef] [PubMed]

87. Bourke, D.; Druckenbrod, R.W. Possible association between donepezil and worsening Parkinson's disease. Ann. Pharmacother. 1998, 32, 610-611. [CrossRef] [PubMed]

88. Shea, C.; MacKnight, C.; Rockwood, K. Donepezil for treatment of dementia with Lewy bodies: A case series of nine patients. Int. Psychogeriatr. 1998, 10, 229-238. [CrossRef] [PubMed]

89. Carcenac, D.; Martin-Hunyadi, C.; Kiesmann, M.; Demuynck-Roegel, C.; Alt, M.; Kuntzmann, F. Extra-pyramidal syndrome induced by donepezil. Press. Méd. (Paris Fr. 1983) 2000, 29, 992-993.

90. Fabbrini, G.; Barbanti, P.; Aurilia, C.; Pauletti, C.; Lenzi, G.L.; Meco, G. Donepezil in the treatment of hallucinations and delusions in Parkinson's disease. Neurol. Sci. 2002, 23, 41-43. [CrossRef] [PubMed]

91. Litvan, I.; Phipps, M.; Pharr, V.L.; Hallett, M.; Grafman, J.; Salazar, A. Randomized placebo-controlled trial of donepezil in patients with progressive supranuclear palsy. Neurology 2001, 57, 467-473. [CrossRef] [PubMed]

92. Kwak, Y.T.; Han, I.W.; Baik, J.; Koo, M.S. Relation between cholinesterase inhibitor and Pisa syndrome. Lancet 2000, 355, 2222. [CrossRef]

93. Paxinos, G.; Watson, C. The Rat Brain in Stereotaxic Coordinates, 5th ed.; Elsevier Academic Press: Amsterdam, The Netherlands; London, UK, 2005; ISBN 0120885727.

94. Schwarting, R.K.W.; Huston, J.P. The unilateral 6-hydroxydopamine lesion model in behavioral brain research. Analysis of functional deficits, recovery and treatments. Prog. Neurobiol. 1996, 50, $275-331$. [CrossRef]

95. Ungerstedt, U.; Arbuthnott, G.W. Quantitative recording of rotational behavior in rats after 6-hydroxy-dopamine lesions of the nigrostriatal dopamine system. Brain Res. 1970, 24, 485-493. [CrossRef]

96. Schallert, T.; De Ryck, M.; Whishaw, I.Q.; Ramirez, V.D.; Teitelbaum, P. Excessive bracing reactions and their control by atropine and L-DOPA in an animal analog of Parkinsonism. Exp. Neurol. 1979, 64, 33-43. [CrossRef]

97. Abedi, P.M.; Delaville, C.; De Deurwaerdere, P.; Benjelloun, W.; Benazzouz, A. Intrapallidal administration of 6-hydroxydopamine mimics in large part the electrophysiological and behavioral consequences of major dopamine depletion in the rat. Neuroscience 2013, 236, 289-297. [CrossRef] [PubMed]

98. Grealish, S.; Mattsson, B.; Draxler, P.; Björklund, A. Characterisation of behavioural and neurodegenerative changes induced by intranigral 6-hydroxydopamine lesions in a mouse model of Parkinson's disease. Eur. J. Neurosci. 2010, 31, 2266-2278. [CrossRef] [PubMed]

99. Schackel, S.; Pauly, M.-C.; Piroth, T.; Nikkhah, G.; Döbrössy, M.D. Donor age dependent graft development and recovery in a rat model of Huntington's disease: Histological and behavioral analysis. Behav. Brain Res. 2013, 256, 56-63. [CrossRef] [PubMed]

100. Jouve, L.; Salin, P.; Melon, C.; Goff, L.K.-L. Deep Brain Stimulation of the Center Median-Parafascicular Complex of the Thalamus Has Efficient Anti-Parkinsonian Action Associated with Widespread Cellular Responses in the Basal Ganglia Network in a Rat Model of Parkinson's Disease. J. Neurosci. 2010, 30, 9919-9928. [CrossRef] [PubMed]

101. Dowd, E.; Monville, C.; Torres, E.M.; Dunnett, S.B. The Corridor Task: A simple test of lateralised response selection sensitive to unilateral dopamine deafferentation and graft-derived dopamine replacement in the striatum. Brain Res. Bull. 2005, 68, 24-30. [CrossRef] [PubMed]

102. Kaindlstorfer, C.; García, J.; Winkler, C.; Wenning, G.K.; Nikkhah, G.; Döbrössy, M.D. Behavioral and histological analysis of a partial double-lesion model of parkinson-variant multiple system atrophy. J. Neurosci. Res. 2012, 90, 1284-1295. [CrossRef] [PubMed]

(C) 2018 by the authors. Licensee MDPI, Basel, Switzerland. This article is an open access article distributed under the terms and conditions of the Creative Commons Attribution (CC BY) license (http:// creativecommons.org/licenses/by/4.0/). 